\title{
How origin, packaging and seasonality determine the environmental impact of apples, magnified by food waste and losses
}

Yanne Goossens ${ }^{1,2}$, Paulien Berrens ${ }^{1}$, Kristof Custers ${ }^{3}$, Steven Van Hemelryck ${ }^{3}$, Karel Kellens ${ }^{4}$, Annemie Geeraerd $^{1,2, *}$

\footnotetext{
${ }^{1}$ MeBioS, Department of Biosystems, KU Leuven, B-3001 Leuven, Belgium

${ }^{2}$ Ethics@Arenberg, Science, Engineering and Technology Group, KU Leuven, B-3001 Leuven, Belgium

${ }^{3}$ Colruyt Group, Edingsesteenweg 196, B-1500 Halle, Belgium

${ }^{4}$ Department of Mechanical Engineering, KU Leuven, Technology Campus Diepenbeek, B-3590 Diepenbeek, Belgium

* Corresponding author. Email: annemie.geeraerd@kuleuven.be, Tel +32 16320591
}

This is a post-peer-review, pre-copyedit version of an article published in The International Journal of Life Cycle Assessment. The final authenticated version is available online at: http://dx.doi.org/10.1007/s11367-018-1522-0 


\begin{abstract}
Purpose. Using apple consumption in Belgium as a case study, this study examines the environmental impacts associated with Belgian (BE) and New Zealand (NZ) apples, how impacts evolve throughout the year and how packaging affects this impact. Additionally, impacts associated with food losses and food waste along the chain are assessed. The study aims to delineate the most important factors determining environmental impacts associated with apple.
\end{abstract}

Methods. The environmental impacts are calculated using the ILCD (International Reference Life Cycle Data System) approach. The functional unit is $1 \mathrm{~kg}$ of apples purchased by a consumer in the supermarket. Primary data was collected through players along the chain. Various scenarios are analysed for both the BE and NZ apple, based on the moment of purchase and packaging method. Food loss and waste impacts are assessed by splitting the impacts along the chain into three categories: apples lost along the supply chain, apples purchased and eaten by the consumer, and apples purchased and wasted by the consumer.

Results and discussion. For all impact categories assessed, NZ apples come at a higher environmental cost than $\mathrm{BE}$ ones due to overseas transport. For both $\mathrm{BE}$ and $\mathrm{NZ}$ apples, minimum impacts are found for bulk apples at the beginning of the season, whereas maximum values are found for pre-packed apples at the end of the season. For $\mathrm{BE}$ apples, the choice of packaging method highly affects the impact, while it is negligible relative to shipping impacts for $\mathrm{NZ}$ apples. Altering secondary packaging materials of $\mathrm{BE}$ apples allows for impacts reductions up to $50 \%$. In the case of climate change, food waste and losses contribute up to $25 \%$ or $15 \%$ for respectively BE or $\mathrm{NZ}$ apples , as all lost food travels in vain through the food chain and needs to be disposed of.

Conclusions. The study shows the importance of origin and packaging, whereas the moment of purchase hardly affects the environmental impact of apples. From a supply chain perspective, there is room for improvement as altering use of secondary packaging greatly reduces impacts along the chain. The study further highlights how impacts are magnified by food waste and losses.

\title{
Keywords
}

Apple; Fresh produce; Origin; Packaging; Seasonality; Food Waste, Food Losses; Food chain 


\section{Introduction}

Our agro-food systems have undergone many changes the last decades following both increased modernisation and mechanisation, as well as lengthening and globalisation of food supply chains. As such, seasonality has become less important and consumers are used to an almost continuous availability of fresh produce in the shops. Unfortunately, this has also led to a disconnection between consumers and their food, and to consumers not knowing who produces their food and how (Loureiro et al. 2002; Ilbery and Maye 2005; Hospido et al. 2009; Huygens et al. 2010; Godfray et al. 2010; Hepting et al. 2013). This means consumers have to rely on the information given to them in order to make food choices (Hepting et al. 2013).

In a previous study we concluded that the current labels on fresh produce in Flanders (Belgium) fail at providing consumers with adequate information on the environmental friendliness of fruits and vegetables (Goossens et al. 2017b). In that paper, we suggested using the life cycle assessment approach (LCA), covering the entire food chain and taking into account multiple impacts, in order to move towards performance based information.

At present, many different methodological approaches are applied within literature, as also highlighted by others (Ingwersen and Stevenson 2012; Ingwersen 2012; Svanes and Aronsson 2013; Keyes et al. 2015). A first issue relates to setting the system boundaries. When it comes to the consumer phase for example, some do consider this life cycle stage (Svanes and Aronsson 2013; Eberle and Fels 2016; Vinyes et al. 2017) while others only to a limited extent (Davis et al. 2011; Longo et al. 2017) or not at all (Milà i Canals et al. 2007; Ingwersen 2012; Keyes et al. 2015). There is even more discrepancy in how the end-of-life stage is being taken into account. In many studies, food waste is not taken into account at all, as highlighted in the review of Cerutti et al. (2014), even though it is associated with a large environmental burden (Gustavsson et al. 2011; FAO 2013). Those studies that do take food waste into account, do so in a very different way. Eberle and Fels (2016) examined the impacts of German food consumption, taking into account the impacts associated with the additional amount of food that needs to enter the food chain because of supply chain losses along the chain, and the environmental burden associated with losses by the consumer. However, impacts associated with disposal of these food wastages and losses was not assessed. In a study on the environmental impacts of the apple and peach chain in the Mediterranean, Vinyes et al. (2017) also examine the impacts of the additional amount of fruits that need to enter the chain whereby all food waste along the supply chain and by the consumer is assumed to be composted; disposal of packaging is however not assessed. In a study on the carbon footprint of bananas, Svanes and Aronsson (2013) took into account food losses along the supply chain and by the consumer using average consumer food waste percentages for fruit rather than a fruit-specific value. When it comes to waste disposal, landfilling of food waste at the packaging plant was considered while for all other food or packaging waste streams, only transport to a treatment facility is taken into account, thus excluding the treatment itself. Hic et al. (2016) and Alexander et al. (2017) go one step further in assessing impacts related to consumer food wastages, by also considering overconsumption as food loss. Next to how to deal with food waste and its disposal, the way the amount of food waste is calculated may also differ, resulting in a wide range of percentage losses found in literature. For apples specifically for example, values as low as $6.5 \%$ and as high as $29 \%$ may be found ((Johnson et al. 2008; defra 2010). Another end-of-life related aspect which may be included within the system boundaries is human excretion and waste water treatment, as argued by Muñoz et al. (2008) and applied by Milà i Canals et al. (2008) and Mithraratne et al. (2008). 
Secondly, also the impact assessment method chosen and the impact categories discussed may vary. Application of the ILCD impact assessment method (International Reference Life Cycle Data System) as put forward by the European Commission seems a rather novel development (Longo et al. 2017; Notarnicola et al. 2017), whereas primary energy use (Jones 2002; Blanke and Burdick 2005; Milà i Canals et al. 2007), the carbon footprint (Mithraratne et al. 2008; Davis et al. 2011; Ingwersen 2012; Svanes and Aronsson 2013; Robertson et al. 2014; Scholz et al. 2015) or ReCiPe (Keyes et al. 2015; Eberle and Fels 2016; Vinyes et al. 2017) have a longer history of use.

The different methodological decisions made, as summarized in the previous paragraphs, complicate comparison of results and hamper using LCA results as a basis for informing consumers. In this context, several harmonization efforts are ongoing, such as the European Product Environmental Footprint (PEF) project (European Commission 2013a).

In our previous paper (Goossens et al. 2017b), we further recommend taking into account situational parameters such as time of consumption, origin, production and distribution mode to assess environmental impacts associated with the particular case of fresh produce.

Using apple consumption in Belgium as a case study, the present study tackles the abovementioned challenges by examining the impacts associated with apples grown both in Belgium (BE) and in New Zealand (NZ), how these impacts evolve throughout the year and how packaging (bulk or pre-packed apples per 6) affects this impact. Additionally, impacts associated with food losses and food waste along the chain are assessed. The study hereby takes into account all life cycle stages, starting from cultivation, over storage and sorting, distribution, packaging and consumer, complemented with end-of-life treatment of food and packaging (both throughout the supply chain and at the level of the consumer). The study aims to delineate the most important factors determining the environmental impact associated with apple. We believe the results of this study can contribute to providing consumers with more adequate environmental impact information. Additionally, the study looks into the impacts associated with secondary packaging as it was found to be a hotspot in many impact categories. As such, even though the focus of this paper is the consumer, the study provides valuable information to the supply chain on how to lower the impact of the apples sold in a regular supermarket.

\section{Methods}

\subsection{Case study description}

The present case study was set up following a collaboration with Colruyt Group, one of the major retailers in Belgium. To ensure year-round supply of apples, Colruyt Group sells both Belgian as well as imported apples. The imported apples make up $40 \%$ of all apples being sold and mainly come from New Zealand, Argentina and France. Selecting the NZ apples allows insight on the impacts associated with counter-season imports over long distance. The share of BE and NZ apples being sold as bulk or as pre-packed apples is listed in Table 1, together with a description of the primary packaging applied. Table 2 provides the market sale of BE and NZ apples (several cultivars) throughout the year. The BE apple is available year-round while the NZ apple is only available 
for 6 months (April - September). The amount of BE apples sold during the year varies each month with lowest numbers occurring during summer; at these moments, highest shares of NZ apples are found.

\subsection{Functional unit and reference flow(s)}

The functional unit (unit of analysis) is $1 \mathrm{~kg}$ BE or NZ apples purchased by a consumer in the supermarket. Impacts are calculated for both bulk and pre-packed apples, and for each month of the year (with NZ apples being available only during 6 months).

For each country of origin, several scenarios are then assessed based on the packaging used and the moment of consumption (Table 3). Scenario $\mathbf{A}$ is the reference flow, referring to $1 \mathrm{~kg} \mathrm{BE}$ or NZ representative apples purchased by a consumer in Colruyt., based on a weighted average of packaging and moment mixes reported in Tables 1 and 2. As such, it provides a first quick view on how the average BE apple performs in comparison with its imported counterpart. Scenario B looks at how the moment of purchase affects the impact. The impact of $1 \mathrm{~kg}$ of apples purchased in the supermarket is examined on a monthly basis whereas for packaging, a weighted average mix based on Table 1 is assumed. Scenario $\mathbf{C}$ looks at how packaging affects the impact. The impact associated with the purchase of $1 \mathrm{~kg}$ bulk or pre-packed apples is examined, using a weighted average mix of the moment of consumption given in Table 2. Scenario D combines the approach of Scenario B and $\mathbf{C}$, looking at how the impact of purchasing $1 \mathrm{~kg} \mathrm{BE}$ and NZ apples evolves throughout the year and this for each of the two packaging methods.

\subsection{Data sources}

Primary data was collected using questionnaires sent to various players along the food chain in collaboration with Colruyt Group (Berrens 2016). The persons contributing to the inventory for this study are listed in Table S1.1 (Online Resource 1). Secondary data was taken from ecoinvent v3.2, available in SimaPro 8 (PRé Consultants, the Netherlands).

\subsection{System boundaries and system description}

This section describes the various life cycle stages, as visualised in Figure 1. This is complemented with the following tables in the supplementary materials (Online Resource 1, Section 1) in order to provide a high level of transparency in the calculations: a detailed listing of the system boundaries (Table S1.2), the resulting data records used for the calculations (Tables S1.3 to S1.6), the parameters used to facilitate scenario calculations related to moment of consumption and packaging (Tables S1.7-S1.8), data records on European freight transport and on electricity mixes used throughout the various life cycle stages (Tables S1.9 and S1.10), and assumptions and data records for packaging (Tables S.11-S.14) and end-of-life (Tables S.15-S.19). Where applicable, the tables indicate the use of confidential primary data.

\subsubsection{Cultivation}

Belgian apples. A broad dataset of integrated production orchards (in their full productive phase) for Jonagold apples and mutants was taken from our previous study (Goossens et al. 2017a). The median yield is 53.5 tonne/ha. In practice, harvest takes place in August for early varieties, whereas others are harvested in September or October. In this study, harvest is assumed to take place in the two weeks harvest window around $1^{\text {st }}$ October. 
New Zealand apples. Confidential input data were received from a farmer in Hawkes Bay (New Zealand) through Enzafruit, an importing and exporting company for pip fruit, located in St Truiden (BE). Harvest is assumed to take place between February and May, depending on the cultivar. The data received refers to one production year for the cultivation of Cripps Pink (sold as Pink Lady), Braeburn and Royal Gala apples, with an average yield of 60 tonne/ha. Embodied impacts related to the production of the inputs were mainly taken from ecoinvent v3.2, while direct field emissions were calculated using IPCC guidelines (IPCC 2006a, b) and methodologies described in the Agri-footprint manual (Blonk Agri-footprint 2015) or ecoinvent reports (Nemecek and Kagi 2007; Nemecek and Schnetzer 2011).

For both BE and NZ apple cultivation, capital goods such as construction and maintenance of the farm building and infrastructure were excluded from the assessment as the impact is believed to be negligible for the present study following depreciation along their lifetime. Additionally, following lack of data, use of wooden poles and hail nets or use of harvest bins were also excluded.

\subsubsection{Storage and sorting}

Belgian apples. After harvest, farmers transport the apples (in a plastic harvest bin) to the auction using a tractor $(90 \%)$ or a truck (10\%), after which they are stored in cooling cells. To do so, apples undergo a first initial cooling phase to rapidly remove the field heat, after which they are stored under Controlled Atmosphere $(\mathrm{CA})$ at $1{ }^{\circ} \mathrm{C}$. We hereby assume that CA storage only takes place for those apples being consumed as of November; apples consumed in October are sold directly to the retail and thus do not go through the initial cooling or CA storage phase. After the long term cooling phase, apples are sorted. This happens either back on the farm premises (80\%) or in an external sorting facility (20\%), thus requiring an additional transportation step (by the farmer, using tractor or truck) to the sorting facility and back to the auction. Apples fit for sale, are loaded into cardboard boxes (50\%) or plastic crates (50\%). Next, the apples stay for an additional 2 days in the auction, after which they are picked up by the buyer (Colruyt Group). Storage losses tend to occur after 1 month of storage at the auction, increasing over time (see further: disposal of food waste).

New Zealand apples. After harvest, farmers transport the apples (in a plastic harvest bin) by truck to a cooling facility. The apples remain in the storage facility in cold rooms (without CA conditions) for two weeks, after which they are sorted. As no data was available on the amount of apples being sorted out, this food waste stream was not modelled separately and losses are cumulatively considered in the next stage based on expert assumptions. Apples fit for sale are loaded into cardboard boxes. The apples are subsequently transported by truck to a nearby port (Napier). After shipment to Belgium (Antwerp), the apples remain in cold storage in the harbour of Antwerp for a maximum of 8 weeks. Note that storage during overseas shipment (which takes about 4 weeks) is included in the life cycle stage "distribution" as this is directly linked to the refrigerated reefer transport. Storage losses tend to occur after 1 month of storage on the reefer ship and following storage at the Antwerp storage facilities (see further: disposal of food waste).

\subsubsection{Distribution and retail}

Belgian apples. From the auction, apples are transported by truck to the Colruyt Distribution Center (DC) in Halle using cardboard boxes or plastic crates (on a wooden pallet). About $40 \%$ of the apples will be sold in bulk and thus remains in the cardboard boxes or plastic crates, while the other $60 \%$ is sent to the packaging facility in Halle 
(see section 2.4.4). The apples remain for about 1 day in a cold space in the DC, after which they are transported by truck to the supermarkets (in cardboard boxes or plastic crates, on a wooden pallet). In the shops, apples are placed in a cold room $\left(7^{\circ} \mathrm{C}\right)$ and remain there for about 1 day. Electricity use for storage in DC and supermarket is allocated on a volume basis, based on estimates by Colruyt Group on the volume share of apples in relation to all products in the cold rooms. Losses occur at different levels along the supply chain, which is discussed in a subsequent section on disposal.

New Zealand apples. Apples are transported overseas in refrigerated reefer ships, using cardboard boxes (on a wooden pallet). In $65 \%$ of the cases, the ship follows a long route (passing several harbours) of 33 days and over $29000 \mathrm{~km}$; in $35 \%$ of the cases, a shorter route of 28 days and about $21000 \mathrm{~km}$ is taken. Upon arrival in the Antwerp harbour, apples are stored in cooling cells (no CA) for up to a maximum of 8 weeks. They are subsequently transported to the DC in Halle using refrigerated trucks, where they stay for up to 3 days. From this moment on, the NZ apples follow the same route as the BE bulk or pre-packed apples. The availability of NZ apples in BE shops follows the harvesting period with apples being harvested between the end of February and the end of May. All apples are stored in NZ for 2 weeks and subsequently shipped overseas for about 4 weeks. Afterwards, they remain in storage in Antwerp for between 0 and 8 weeks. As such, NZ apples are available in the shops from April until September. The scenarios investigated related to NZ apples thus only concern these months (while for BE apples, year-round availability is assured and thus examined).

\subsubsection{Packaging}

Primary packaging. For bulk apples, this includes the plastic bags (4.90 g polyethylene) available in the shop for consumers to put their apples in. For pre-packed apples, primary packaging refers to a cardboard tray (21.00 g) and a plastic film (3.21 g polyethylene) which is applied at the packaging facility in the DC. Tables S1.11 and S1.12 (Online Resource 1) provide an overview of the assumptions and data records created for the primary packaging materials. Losses of packaging materials occur at the level of the DC and supermarket (see further: disposal stage).

Secondary packaging. The use of plastic crates and/or cardboard boxes is taken into account. According to information from the Colruyt Group, half of the BE apples that come from the auction, arrive at the DC in medium sized plastic crates ("EPS M, medium", blue rigid tray (EPS 2017)), while the other half comes in cardboard boxes. Apples that will be sold as bulk remain in these crates or boxes, while pre-packed apples are transferred to larger sized plastic crates ("EPS H, high") after packaging. The pre-packed apples thus require two sets of secondary packaging: one for the distribution up until arrival at DC, and one for the distribution after packaging into apple trays at the DC.

Imported apples are transported overseas in cardboard boxes (assumed to be similar to the ones used above for BE bulk apples). Upon arrival in DC, they follow the same route as the BE apples, depending on whether they will be sold as bulk or pre-packed apples: bulk apples remain in the cardboard boxes, while pre-packed apples are transferred to EPS H crates. Tables S1.13 and S1.14 (Online Resource 1) provide more information on the assumptions and data records created for secondary packaging. 
Tertiary packaging. Impacts related to the production (and reuse) of tertiary packaging, such as the use of wood pallets, are believed to be negligible as the impact can be depreciated along their lifetime. As such, these are excluded from this study. Along the same lines, production and reuse of plastic or wood harvest bins ("paloks") used for harvesting and during long term storage, were also excluded. The weight of the harvest bins and of the wooden pallets was however taken into account during transport: $45 \mathrm{~kg}$ for a paloks which fits $350 \mathrm{~kg}$ apples (BFV 2017) and a pallet of $22 \mathrm{~kg}$ carrying 36 cardboard boxes or plastic crates (Barthel et al. 2007).

\subsubsection{Consumer}

The consumer drives to the shop by car (return trip of 2 times $5 \mathrm{~km}$ ), where he/she buys $1 \mathrm{~kg}$ bulk or pre-packed apples (assumptions based on data provided by Colruyt Group). The allocation factor for the impact of using a passenger car is calculated based on guidance from European Commission (2016), using the volume of $1 \mathrm{~kg}$ apple as a ratio to a default trunk volume whereby the maximum volume to be considered for transport of goods by consumers is $0.2 \mathrm{~m}^{3}$ (around 1/3 of a trunk of $0.6 \mathrm{~m} 3$ ). Upon arrival at home, the apples are assumed to be stored in a household fridge for 3.5 days (modified from default value of 7 days from European Commission (2016)). Energy consumption of the fridge is quantified based on LCI-data from the European Commission (2016). Disposal of food and packaging waste by the consumer is discussed in the next section.

\subsubsection{Disposal along the supply chain and by the consumer}

Packaging losses and packaging waste management. Throughout the supply chain, primary packaging for bulk apples is lost at the level of the supermarket as for example a small share of the plastic bags falls on the floor. For pre-packed apples, losses occur both at the level of the DC, where broken cardboard trays and leftover plastic foil are thrown, and at the supermarket in case of unsold pre-packed apples. Additionally, both at the DC and supermarket, secondary packaging waste is collected and disposed of. Primary packaging waste at the level of the consumer relates to disposal of a plastic bag in case of bulk apples or a cardboard tray and plastic foil in case of pre-packed apples. Table S1.15 (Online Resource 1) lists the losses and packaging waste for primary packaging in the relevant life cycle stages; Table S1.16 describes in detail the various waste streams related to disposal of primary and secondary packaging waste, while Table S1.17 provides a closer look at the data records created within SimaPro.

Food losses and food waste management. Food is lost at various steps along the supply chain. An additional amount of apples therefore needs to enter the food chain in order to have $1 \mathrm{~kg}$ apples available for sale at the shop. When it comes to on-farm losses, no data was available and its waste management could therefore not be quantified. The additional amount of apples that needs to be cultivated to account for these field losses is however taken into account as the impacts associated with the cultivation stage as calculated in our previous study (Goossens et al. 2017a) refer to those impacts for cultivating both the harvested and the non-harvested (field loss) apples. The loss percentages for the remainder of the supply chain as provided to us by the auction (BFV and BelOrta), the importing company (Enzafruit) and by the retailer (Colruyt Group), are shown in Figure 2. Upon arrival at the DC, distinction is made between the apples in bulk and the ones destined to be packaged. At this point, pre-packed apples are sorted whereas bulk apples are not and therefore deficiencies and damages are not noticed at the DC. This is why in the next step, at the supermarket, more bulk apples are thrown away compared to pre-packed apples. Another factor contributing to higher loss percentages for bulk apples at the supermarket is that these are more prone to bruising by retail handlers and consumers than the prepacked apples. Nevertheless, 
it should be noted that for pre-packed apples in the shop, the detection of one spoiled apple always leads to disposal of the entire package of six apples and thus of the disposal of potentially good quality apples. These food wastes are managed in different ways: losses from on-farm sorting are composted whereas losses at the external sorting facility, DC and supermarket are sent to an anaerobic digestion facility (Tables S1.18 and S1.19, Online Resource 1).

Based on the loss percentages throughout the year and at each level of the food supply chain, Figure 2 further shows the total amount of apples that needs to enter the food chain to ensure that $1 \mathrm{~kg}$ apples can be purchased by the consumer. At the end of the season, an additional amount of $67 \mathrm{~g}$ and $56 \mathrm{~g}$ of respectively BE and NZ prepacked apples needs to enter the food chain at the level of the auction or storage facility.

Next to losses along the supply chain, the consumer also contributes to food waste as about $6.5 \%$ of the apples that are bought, and hence were suitable to be eaten at the moment of purchase, are in the end thrown away as a whole because the consumer deems it to be "inedible" (Johnson et al. 2008; WRAP 2008). This percentage does not consider waste following the disposal of the so-called "unavoidable waste" such as skin and apple core (WRAP 2008). Additionally, following lack of data, no distinction could be made between losses for bulk apples versus pre-packed apples which may be more protected and thus less prone to bruises. Consumer food wastage is disposed of as municipal biowaste (43\%), municipal household waste $(21 \%)$, or composted at home (36\%) (personal communication with Vlaco, the Flemish compost organisation; Tables S1.18 and S1.19, Online Resource 1).

\subsection{Impact assessment method}

\subsubsection{Impact along the chain}

All impact calculations were performed using SimaPro 8, after which scenario analyses and graphs were made using the statistical software JMP Pro 12 (SAS Institute Inc., NC, USA). The ILCD impact assessment method has been applied, leading to results in 16 midpoint impact categories (ICs). Results are analysed for the climate change impact category (CC) as well as for those impact categories that can be considered to be most relevant based on their contribution to the single score impact, thereby following the PEF guidelines (European Commission 2013b, 2016), as explained in Online Resource 1 (Section 2). For BE apples, the most relevant ICs were identified to be particulate matter (PM), ionising radiation human health (IRHH), acidification (AC), freshwater eutrophication (FEU), marine eutrophication (MEU) and mineral, fossil and renewable resource depletion (MD). For NZ apples, the relevant ICs are photochemical ozone formation (POF), AC, terrestrial eutrophication (TEU), MEU and MD. In the analysis, focus will be given to the hotspots which are those (sub)life cycle stages that cumulatively contribute at least to $50 \%$ of the impact in a certain IC (European Commission 2016; ECOFYS et al. 2017).

\subsubsection{Food waste along the chain}

The additional amount of apple that needs to enter the food supply chain is often associated with substantive impacts, which can be considered to be "useless" since it is linked to food that is later on lost along the chain. The further in the chain food is lost, the more impact is associated with it since each step along the chain adds up to it. Additionally, all food wasted needs to be disposed of, resulting in additional impacts associated with managing 
this food waste. In this study, the impacts associated with treatment of these food wastes is taken into account. Potential benefits associated with food waste treatments, such as the possibility for using compost to substitute fertiliser use in farming or the generation of electricity from anaerobic digestion were however not considered.

All impacts associated with food waste and disposal along the supply chain and by the consumer are calculated by allocating the impacts on a mass basis between losses and consumption (Eberle and Fels 2016): impacts associated with apples lost along the supply chain, with apples purchased and eaten by the consumer, and with apples purchased and wasted by the consumer. We hereby note that at least a part of the losses is inevitable, considering the perishable nature of fresh produce.

\section{Results}

\subsection{Effect of taking into account origin, packaging and moment of purchase}

Figure 3 shows the life cycle impact associated with $1 \mathrm{~kg}$ average BE or NZ apples within Scenario A. The impacts associated with BE apples are lower than for the imported counterparts, and this for all ICs assessed (detailed results: Online Resource 2, sheet 1).

While Scenario A gives an indication of the impact associated with "an average BE or NZ apple", Scenarios B, C and $\mathrm{D}$ allow analysis of the effect of moment of purcahse and/or packaging method. Table 4 shows the minimum and maximum values found within Scenarios B, C and D (detailed results: Online Resource 2, sheet 2-4) whereas Figure 4 visualises how the impact for both BE and NZ apples evolves throughout the year and for two packaging methods (Scenario D). Throughout the year (Scenario B), impacts increase with increasing time after harvest, with maximum impacts found in September for both BE and NZ apples. Comparing the two packaging methods (Scenario C), shows that both for BE as well as for NZ apples, bulk apples are always associated with a lower impact than their pre-packed counterparts. Looking at all possible combinations of packaging method and moment of purchase (Scenario D), minimum values are found for bulk apples in the beginning of the season (October for BE and April for NZ) whereas maximum values are associated with pre-packed apples at the end of the season, in September. Comparing the maxima for BE apples within each scenario with the minima for NZ apples, further shows that, from an environmental perspective, a BE apple is preferable over a NZ apple at any moment of the year and for any packaging method.

\subsection{Identification of hotspots}

Figure 5 visualises the percentage contribution of each life cycle stage to the total impact associated with $1 \mathrm{~kg}$ BE and NZ apples (Scenario A, reference flow). In order to identify the hotspots (contributing cumulatively to more than $50 \%$ of the impact) along the chain, the life cycle stages are further divided into sub-life cycle stages. Table 5 provides an overview of the relative contribution of each of these sub-life cycle stages to the environmental impact of the entire chain within Scenario A for the relevant ICs. The hotspots are discussed here below, structured per life cycle stage they belong to (see Online Resource 2, sheets 5-8 for results for all scenarios in detail). 


\subsubsection{Cultivation}

Cultivation is a hotspot for the BE average apple in five out of seven ICs assessed (Scenario A): CC, PM, AC, FEU and MEU. Following the scope of this study, the cultivation stage was not examined in detail; more information can be found in our previous study (Goossens et al. 2017a).

\subsubsection{Storage and sorting}

Long term storage of the average BE apple (Scenario A) is a hotspot for IRHH following use of electricity (90\% regular BE power grid, combined with $10 \%$ solar). Comparing packaging methods and moment of consumption (Scenario D), shows that storage is only a hotspot as of January for BE bulk apples or as of December for BE prepacked apples (see Online Resource 2, sheet 8). This is logic since at the beginning of the season, storage duration is short (or non-existing) and thus electricity consumption is low (or non-existing).

\subsubsection{Distribution}

Overseas transport and cooling is a hotspot in all six ICs assessed for NZ apples (no matter which packaging method or moment of consumption). In Scenario A, this sub-stage contributes between $61 \%$ and $90 \%$ to the overall impact along the chain. Due to its high contribution, it is even the only hotspot for the NZ apple chain. Looking for example at the CC impact of an average $\mathrm{kg} \mathrm{NZ}$ apples, the overseas refrigerated shipment is responsible for $0.9 \mathrm{~kg} \mathrm{CO}_{2}$-eq, which is more than twice the total $\mathrm{CC}$ impact of the $\mathrm{BE}$ apple chain. If we were to exclude the overseas transport, the $\mathrm{CC}$ impact of both apple chains would already be closer to each other, with the BE apple still being slightly more climate friendly than its imported counterpart. When it comes to AC, exclusion of the overseas shipment for NZ apples would even lead to an impact that is $12 \%$ lower than the AC impact of BE apples. In other ICs however, such as MEU or MD, subtracting the overseas shipment impact, still results in a total impact of the NZ apple being respectively $18 \%$ or $46 \%$ higher than the BE apple following high impacts associated with packaging and disposal along the supply chain of $\mathrm{NZ}$ apples.

\subsubsection{Packaging}

Table 6 shows that in Scenario C, the impact associated with primary packaging materials for $1 \mathrm{~kg} \mathrm{BE}$ or NZ prepacked apples is between two to almost eleven times that of bulk apples, depending on the IC assessed. Primary packaging material for $1 \mathrm{~kg}$ bulk apples (4.90g plastic bag) is thus more environment friendly than their prepacked counterparts $(3.21 \mathrm{~g}$ plastic foil $+21.00 \mathrm{~g}$ cardboard tray). This is particularly true for the MD impact, following use of cardboard materials for the pre-packed apples. Note that the packaging phase only focuses on the materials and the packaging process itself; end-of-life of packaging materials is dealt with in a separate life cycle stage (the disposal stage).

When it comes to packaging, more important than primary packaging is the use of secondary packaging. In five out of seven ICs assessed for an average $\mathrm{kg}$ of BE apples (Scenario A), secondary packaging was found to be a hotspot: CC, PM, AC, FEU and MD. Main contributor to these impacts is the production of the corrugated board boxes. Again, both for BE as well as NZ apples in Scenario C, secondary packaging of bulk apples is associated with a lower impact than that of pre-packed apples (Table 6). This is mainly because pre-packed apples require two steps of secondary packaging while bulk apples only one. 
Even though secondary packaging is not a hotspot for NZ apples, it is the second biggest contributor to the total chain impact of NZ apples in four out of six ICs assessed in Scenario A (Table 5). In all ICs assessed for both BE and NZ apples, the absolute impacts associated with secondary packaging of NZ apples are higher than those of BE apples. This can be explained by the higher share of pre-packed NZ apples (for which secondary packaging generates a higher impact than bulk apples, see above) within the reference chain of Scenario A. Additionally, NZ apples arrive at the DC in cardboard boxes. As such, those apples destined for pre-packed apples must all be repacked into EPS crates for further distribution into the shops, after which the cardboard boxes are discarded. The BE apples however, arrive at the DC in both cardboard boxes and EPS crates. Thus, a smaller amount of cardboard boxes is being discarded, while the EPS M boxes do not need to be discarded but are sent back into the European pool system for reuse.

\subsubsection{Disposal along the supply chain}

Disposal along the supply chain is a hotspot for the average BE apple in the CC and FEU impact categories (Scenario A). Disposal of packaging waste is of minor importance as disposal of food along the supply chain makes up 88 or $90 \%$ respectively of the CC and FEU disposal impacts along the supply chain (Online Resource 2, sheet 9). The remaining impact associated with disposal along the supply chain is almost entirely attributable to the disposal of secondary packaging since disposal along the supply chain of primary packaging is very limited $(<0.5 \%)$ following the small amounts of packaging materials lost along the supply chain.

Scenario C further shows that in both ICs, the disposal impacts are larger for pre-packed apples than for bulk apples. Greatest differences are found in food waste disposal whereby the CC and FEU impacts for food disposal associated with pre-packed apples are about 1.8 times those for bulk apples (Online Resource 2, sheet 9).

\subsubsection{Consumer}

The consumer impact (in absolute value) remains the same throughout all scenarios assessed, as it does not change when packaging or moment of consumption alters. The consumer phase is a hotspot in four out of seven ICs assessed for the average BE apple (Scenario A): CC, PM, IRHH and MD. For the IRHH impact category, the main contributor was consumer storage in a household fridge $(92 \%)$ powered by the regular BE power grid (following use of nuclear energy). In the other ICs, passenger transport is responsible for between 60 and $83 \%$ of the consumer impact.

\subsubsection{Disposal by the consumer}

Disposal by the consumer of packaging and food waste is not a hotspot for neither BE nor NZ apples. Disposal of food always has the same absolute impact, regardless of the packaging method and moment of consumption, as it is assumed that, per kg apples bought, $65.00 \mathrm{~g}$ of it is lost (source: Johnson et al. 2008; WRAP 2008). Disposal of packaging waste however depends on the packaging method applied (Scenario C): for bulk apples, the plastic bag of $4.90 \mathrm{~g}$ ends up in municipal incineration, while for pre-packed apples, this waste stream is used to a lesser extent (smaller weight of plastic foil, namely 3.21g) complemented with a paper/cardboard waste stream for the cardboard tray. The CC impact of disposal of packaging waste of pre-packed apples is slightly lower than that of bulk apples following the smaller amount of plastic foil (as compared to the plastic bag for bulk apples) being sent to municipal incineration and following the relatively low CC impact associated with the cardboard tray waste stream. In all other ICs, disposal of packaging waste of pre-packed apples is higher than of bulk apples, going up 
to 465 times as high in the case of MD (Online Resource 2, sheet 9) following the relatively high impacts associated with the cardboard tray waste stream.

Looking at the contribution of food and packaging waste to the life cycle stage of disposal by the consumer, food disposal is the greatest contributor for bulk apples in all impact categories assessed. For pre-packed apples however, disposal of packaging waste generates the largest impact in the impact categories PM, IRHH and MD, up to $99 \%$ in the case of MD (Online Resource 2, sheet 9).

\subsection{Food waste along the chain}

Figure 6 visualises, for Scenario A, how the impacts for the entire apple chain can be divided into impacts associated with apples lost along the supply chain (and thus never purchased), apples purchased and eaten by the consumer, and apples purchased but lost and thus never consumed. The impacts associated with food waste of NZ apples are larger than those of BE apples because of the high impacts associated with overseas transport with each $\mathrm{NZ}$ apple wasted relating to an apple that was shipped overseas in vain. For climate change for example, $0.10 \mathrm{~kg}$ $\mathrm{CO}_{2}$ eq is associated with the share of $\mathrm{NZ}$ apples that enters the food chain but never makes it to the consumer. Another $0.10 \mathrm{~kg} \mathrm{CO}_{2}$ eq is associated with the share of $\mathrm{NZ}$ apples that does make it to the consumer but is in the end thrown away. In total, these impacts represent about $16 \%$ of the total chain impact of an average kg NZ apples (Online Resource 2, sheet 10). For BE apples, the CC impacts associated with food waste are respectively 0.05 $\mathrm{kg} \mathrm{CO}_{2}$ eq and $0.04 \mathrm{~kg} \mathrm{CO}_{2}$ eq., which represents about $25 \%$ of the total chain impacts of BE apples. Thus, only $75 \%$ or $85 \%$ of the CC impact associated with respectively BE or NZ apples corresponds to apples that are effectively consumed. Relatively spoken, the impacts associated with food waste of BE apples is worse than that of NZ apples, whereas in absolute values, losses of NZ apples are more impacting. Detailed impact values for food waste along the chain can be found in Online Resource 2 (sheet 11).

\section{Discussion}

Our previous study (Goossens et al. 2017a) examined the cultivation stage of apples in detail, taking into account the specificities of perennial production systems. This study completes our apple case study by looking at the entire apple chain, including all steps beyond cultivation and including food and packaging waste. The research aims at tackling the methodological challenges identified in the introduction section, relating to setting the system boundaries and to assessing a wide range of impact categories. Additionally, we take into account various situational parameters as we examine the impacts associated with apples grown both in Belgium (BE) and in New Zealand (NZ), how these impacts evolve throughout the year and how packaging (bulk or pre-packed apples per 6) affects this impact. As such, this study contributes to the existing food LCA literature and to informing consumers on the environmental impact of fresh produce.

\subsection{Impact along the chain}

Looking at climate change impacts of apples consumed within the country of production, the following impacts are found in literature: $0.2 \mathrm{~kg} \mathrm{CO}_{2}$ eq for $1 \mathrm{~kg}$ Swedish apples (Davis et al. 2011) and $0.3 \mathrm{~kg} \mathrm{CO}_{2}$ eq per kg Spanish apples (Vinyes et al. 2017) whereas our results lead to a climate change impact of about $0.4 \mathrm{~kg} \mathrm{CO}_{2}$ eq per $\mathrm{kg} \mathrm{BE}$ 
apples. The results from Longo et al. (2017) on Italian apples are slightly higher at $0.6 \mathrm{~kg} \mathrm{CO}_{2}$ eq per $\mathrm{kg}$. This may be due to different system boundaries being applied (as described in the introduction section) and due to the fact that the authors consider distribution to both national as well as international markets. Looking at other impact categories, the Spanish apples lead to MEU impacts almost double of our BE apples and to FEU impacts which even differ by 5 orders of magnitude (Vinyes et al. 2017). In that study, the agricultural phase is the largest contributor in 13 out of 18 environmental impact categories assessed whereas in our study, this is only the case in two out of seven categories assessed for BE apples as in the other categories, packaging and the consumer are the biggest contributors. Milà i Canals et al. (2007) highlight the importance of including packaging into the assessment, as packaging would contribute to between 43 and $65 \%$ of the primary energy use along their supply chain, depending on moment of consumption and country of origin of the apples. In the present study, packaging also contributes considerably to the entire chain impact of BE apples.

Focusing on import produce, Mithraratne et al. (2008) concluded that total greenhouse gas emissions associated with NZ kiwifruit consumed in the UK are at $1.62 \mathrm{~kg} \mathrm{CO}_{2}$ eq per kg kiwi which is of the same magnitude as the $\mathrm{NZ}$ apples in this study ( $1.33 \mathrm{~kg} \mathrm{CO}_{2}$ eq per $\mathrm{kg}$ apples) despite the differing fruit and system boundaries (exclusion of re-packing in Europe; higher food loss along the supply chain). The study from Svanes and Aronsson (2013) on bananas produced in Costa Rica and sold in Norway also provides comparable results as $1 \mathrm{~kg}$ bananas sold in Norway leads to a carbon footprint of $1.37 \mathrm{~kg} \mathrm{CO}_{2}$ eq. In the present study, the overseas shipping stage contributed to $0.9 \mathrm{CO}_{2}$ eq per $\mathrm{kg}$ apple, which is only slightly higher than the impacts found in literature: $0.7 \mathrm{~kg} \mathrm{CO}_{2}$ eq per $\mathrm{kg}$ NZ kiwi consumed in the UK (Mithraratne et al. 2008), $0.65-0.67 \mathrm{~kg} \mathrm{CO}_{2}$ eq per $\mathrm{kg}$ NZ kiwi imported in Germany (Robertson et al. 2014), and $0.75 \mathrm{~kg} \mathrm{CO}_{2}$ eq per kg Costa Rican bananas shipped to Norway. Differences are most probably due to the (slightly) smaller shipping distances applied in literature.

In line with our results, many studies conclude that domestically sourced apples have a better environmental performance than those imported from overseas, even when taking into account long term storage (Jones 2002; Blanke and Burdick 2005; Sim et al. 2007). In all cases, long distance shipping of apples is a major contributor to the impacts. When it comes to consumption in the UK, Jones (2002) finds an up to 20-fold energy saving in the transport life-cycle for UK grown apples over imported apples from the US. Sim et al. (2007) further found that transport of Chilean and Brazilian apples contributes to respectively $72 \%$ and $90 \%$ of the climate change impact of the supply chain as compared to 6-21\% for UK apples. When it comes to consumption in Germany, supply chain transport of German apples contributes to only $7 \%$ of the total primary energy use along the chain, while this share increases up to $47 \%$ for NZ apples (Blanke and Burdick 2005). Saunders and Barber (2008) on the other hand conclude that $\mathrm{NZ}$ apples imported in the UK perform better than UK apples. This is due to the low carbon emissions assumed for refrigerated sea transport: replacing this value with the emissions used in the present study (as taken from ecoinvent v3.2) would change the results considerably to the UK apple being more climate friendly.

Most LCA studies are case studies, with the inventory being based on a single input value, while in practice, this value may be slightly higher or lower and each parameter could be represented by a probability distribution. As such, when focusing on only one parameter value, some uncertainty surrounds the results. This is also the case for the present study which is based on the data values provided to us by experts in the field and/or players along the apple chain, often complemented with assumptions. Following lack of information, the potential ranges of values of each parameter within the inventory could not be taken into account. Milà i Canals et al. (2007) showed 
how integration of such variability may affect ranking of products' environmental performance. The authors found that in August, when taking into account variability of the parameters used in the inventory, the ranges of primary energy use associated with UK and NZ apples consumed in the UK overlap and consumption of NZ apples may be less energy consuming than domestic apples. In that study, higher productivity of NZ apple production is assumed, which could not be confirmed in our study as climate change impacts for cultivating BE and NZ apples were quite similar. Also, the authors assume large storage losses (up to $25 \%$ after 10 months storage) which highly affects the impact of the UK apples in August as in such a case a higher amount of apples needs to enter the chain.

Milà i Canals et al. (2007) further looked into how apples imported into the UK from another EU country would perform compared to NZ apples, taking into account parameter variability: in April, impacts are very similar whereas in August, the import apples from within the EU even led to higher median impacts than those imported from NZ, most probably following the high storage losses of the EU apples. For our study, it would be interesting to assess how apples from for example France, imported into BE, would perform compared to BE ones, based on the additional transport steps that occur (and taking into account the specificities of cultivation in FR).

Beyond the discussion of domestic versus imported produce, it may also be interesting to look at how local systems perform, such as buying apples directly at the farm rather than in a supermarket. In that case, both the technologies used during production, as well as the distribution modes will affect the impact rather than the distances travelled (Van Hauwermeiren et al. 2007; Mundler and Rumpus 2012; Röös and Karlsson 2013).

Additionally, it could be interesting to perform a sensitivity analysis of how the results of the case study would be affected when switching to other energy sources, such as switching to $100 \%$ solar energy throughout the supply chain (see also calculations made in Section 1.5.2 of Online Resource 1). Other interesting scenarios to assess relate to changing storage conditions of the apples, to for example storage in a basement.

\subsection{Food waste}

The present results for food waste by consumers are based on the assumption of $6.5 \%$ consumer waste. As mentioned in the introduction section, some literature sources found consumer waste for apples to be as high as 29\%. In that case, the impacts associated with apples that travelled through the supply chain but were in the end thrown by the consumer would at least quadruple. Additionally, because of the additional amount of apples that is being disposed of, the total chain impacts would increase as well. In that case, disposal by the consumer could become a hotspot as well, in particular in the CC category for BE apples, as the current contribution of disposal by the consumer is found to be $9 \%$.

Cuellar and Webber (2010) calculated the energy intensity of food production in the US, concluding that in 2007, about $25 \%$ of energy were embedded in wasted food. These results are similar to our results for climate change, even though our study also considers impacts associated with disposal of wasted food, in contrary to the aforementioned study, and is based on lower loss percentages. In their study on food consumption and waste in Germany, Eberle and Fels (2016) calculate that, for each kg of fruit being sold, $1.12 \mathrm{~kg}$ needs to be harvested (or $1.4 \mathrm{~kg}$ needs to be cultivated when including field losses). This value is however assumed to be applicable to the category of fruits as a whole, which may explain why it is slightly higher than what is used in our study for apples. The authors further conclude that food losses along the value chain account for 14 to $20 \%$ of the environmental 
burden of food consumption, depending on the impact category. For climate change for example, about $15 \%$ of the impacts associated with in-house consumption in Germany is attributable to food losses whereas in our study, this share is $15 \%$ for NZ apples consumed in Belgium and goes up to $25 \%$ for BE apples. In their study on apple and peach production and consumption in Spain, Vinyes et al. (2017) state that $1.17 \mathrm{~kg}$ fruit needs to be harvested (or $1.21 \mathrm{~kg}$ including field losses) for each $\mathrm{kg}$ fruit on the market, based on a total of $15 \%$ retail losses. For the consumption stage, losses are considered to be $17 \%$. Climate change impacts related to food losses along the supply chain are responsible for $0.018 \mathrm{~kg} \mathrm{CO}_{2}$ eq, whereas consumer wastage contributes to $0.012 \mathrm{~kg} \mathrm{CO}_{2}$ eq. Despite the higher percentage losses, these values are lower than the climate change impacts associated with apple losses for domestic consumption in our study.

Impacts associated with anaerobic digestion of food waste were calculated using the existing ecoinvent datarecord "Biowaste, treatment of manure and by anaerobic digestion". Following the focus of this study, no new data record specifically on anaerobic digestion of food waste was built even though we could expect the impacts, in particular the eutrophication impacts, associated with manure and food waste to differ. It would be interesting to refine the present case study with such a specific dataset in future research. Additionally, we suggest looking into the potential benefits resulting from these food waste treatments, such as the possibility for using compost to substitute fertiliser use in farming or the generation of electricity from anaerobic digestion of food waste.

\subsection{Potential for reducing the impact along the chain}

\subsubsection{Taking into account situational parameters}

Lowest impacts are found for BE apples, as compared to their imported counterparts from NZ. This is the case at each moment of the year and for both packaging methods. Furthermore, for both BE and NZ apples, minimum and maximum impact values in each IC assessed were found for respectively bulk apples in the beginning of the season and pre-packed apples at the end of the season. Figure 7 shows the extent to which the choice of packaging method and/or moment of purchase can affect the impact of the apples we buy, depending on the impact category assessed. This is done through comparison of the minima and maxima found within Scenarios B, C and D (see also Table 4) with the impact values found within Scenario A ("the average kg BE or NZ apples"). Full results are given in Online Resource 2 (sheet 12).

When it comes to BE apples, moment of purchase (Scenario B) clearly affects the IRHH impact with a maximal reduction of $27 \%$ achieved by buying apples only in the beginning of the season as compared to the current consumption pattern. Purchasing only apples at the end of the season, would lead to a $36 \%$ increase of the IRHH impact. For the other impact categories, the relative reductions are a lot smaller, with maximal reductions ranging between 2 and $6 \%$. What does however clearly affect the impact, is the choice of packaging method: in five out of seven ICs assessed, the reductions to be achieved by consuming only bulk apples rather than the packaging mix (with $60 \%$ pre-packed apples) that is currently consumed, are in the magnitude of $10 \%$ or higher. Combining the two options, namely consumption of apples only in the beginning of the season and buying bulk apples, would lead to reductions of over $10 \%$ in all but one IC (MEU). 
When it comes to NZ apples, moment of purchase hardly affects the impact. Greatest reductions can be achieved by buying only bulk apples rather than the packaging mix (with $77 \%$ pre-packed apples) that is currently consumed; reductions are however smaller than for BE apples.

\subsubsection{Altering use of secondary packaging}

Packaging, and in particular secondary packaging, is a large contributor to the impact of the entire chain. Additionally, secondary packaging was identified as a hotspot in five out of seven ICs assessed for BE apples, with great impacts coming from the use of the single use cardboard boxes. This section therefore assesses the effect of switching towards using only EPS boxes, which are reusable, as secondary packaging. Since use and reuse of EPS plastic crates is organised within a European pool system, this alternative case scenario is only assessed for BE apples.

At this moment, after sorting, half of the BE apples is distributed to the DC in EPS M boxes and half in cardboard boxes. This alternative scenario therefore refers to zero use of cardboard, and to using only EPS (EPS M) boxes for the first step of secondary packaging of apples at the auction or sorting facility. For the subsequent steps along the chain, no changes are assumed to take place. The switch to using only EPS boxes for secondary materials affects both material use at the level of the auction or sorting facility, as well as disposal of secondary materials at the supermarket or DC.

Figure 8 shows how the total impact along the chain decreases when switching to $100 \%$ EPS M boxes for secondary packaging at the auction or sorting facility. Detailed results, including how this affects packaging and disposal impacts, can be found in Online Resource 2 (sheet 13). As expected, greatest reductions are found for these ICs for which secondary packaging was identified as being a hotspot (as indicated with an asterisk in the graph: CC, PM, AC, FEU and MD). For the climate change impact for example, reductions of 9-10\% are found. Reductions become even larger in the other "hotspot-ICs" with greatest reductions found within MD: the impact associated with $1 \mathrm{~kg}$ apples can (almost) be halved through changes in secondary packaging. Along the same lines, Ingwersen (2012) has also shown the potential for impact reduction (across all impact categories assessed) when replacing single use boxes for secondary packaging of pineapple with reusable ones. Examining the impacts associated with replacing the single use cardboard boxes with single use plastic crates was out of scope of this research; we could however expect the reductions to be far lower (or non-existent) following the use of fossil resources for the production of the plastic crates as compared to the renewable resources (wood chips) used for cardboard production.

Within Belgium, packaging used for apples is rather similar amongst retailers. As such, the results obtained within this study can be expected to also apply to other retailers. It would be interesting to - in the future - see which other packaging systems exist within Europe (or worldwide) and extend this study with this new knowledge.

\subsubsection{Food waste reduction and/or improved waste management}

The most obvious way to reduce food waste impacts is reducing the amount of food waste generated along the supply chain. As such, a smaller amount of apples needs to be cultivated, stored, transported and packed in order to have $1 \mathrm{~kg}$ of apples to be purchased by the consumer. A recent report by Hanson and Mitchell (2017) showed that for companies, the financial return of investment is high. For food retailers for example, every euro or dollar 
invested in reducing food loss and waste, can lead to a return of between 5 and 10 euro or dollar. Reducing the amount of food thrown by the consumer further avoids generating "useless" impacts along the apple chain.

Next to the useless impacts related to cultivating, storing, transporting and packing apples, the generation of food waste also requires disposal of these wastes, both at the level of the supply chain and at the consumer. Disposal of food losses along the supply chain is particularly relevant for the FEU impact category. From Figure 6 it is clear that the "not purchased" FEU impacts are as high as 22\% for $1 \mathrm{~kg}$ average BE apples (Scenario A). Almost $90 \%$ of these impacts (or $19 \%$ of the entire chain impacts) stem from disposal of the food that was lost (Online Resource 2, sheet 9). For the CC impact of BE apples, disposal of food waste along the supply chain contributes to about $11 \%$ of the total chain impacts. Food waste management along the supply chain now refers to anaerobic digestion or home composting (Table S.18, Online Resource 1) with home composting having a much lower CC and FEU impact. Nevertheless, home composting along the supply chain is currently assumed to be applied only for food waste generated after sorting of apples at the farm whereas sorting losses at the auction/external sorting facility and losses at DC and the supermarket are treated using anaerobic digestion. From the FEU and CC viewpoint, it may be interesting to strive towards using food disposal options with a lower impact. We therefore suggest assessing the impacts associated with composting on a larger, industrial scale, as would be required for composting food waste along the supply chain, to see whether or not this would be less impacting than anaerobic digestion. An analysis of which options may be valuable was however out of scope of this paper. When it comes to $\mathrm{NZ}$ apples, the contribution of food disposal along the supply chain within Scenario A is a lot smaller, following the large contribution of overseas shipping. In absolute terms however, the food disposal impacts within the CC impact category are larger than those of BE apples (the FEU impact is not assessed for NZ).

At consumer level, almost $7 \%$ of the CC impact of BE apples is associated with food waste disposal by the consumer. In absolute numbers, this impact is the same for NZ apples (although in relative terms, this process only contributes to less than $2 \%$ of the total NZ chain impact). Currently, a mix of municipal biowaste collection, home composting and municipal household waste is assumed (Table S.18, Online Resource 1). Here as well, there might be room for improvement in how to handle food waste at consumer level.

\section{Conclusions and recommendations}

For our conclusions, we focus on the options a consumer has when buying apples throughout the year. Additionally, we touch upon a few options for the supply chain for reducing the environmental impact of these apples and for more sustainable sourcing by retailers.

Taking into account origin. For each of the relevant ICs, the impact associated with BE apples is always lower than that of NZ apples, no matter when the apples are consumed or which packaging is applied. Thus, from an environmental perspective, we discourage overseas shipping of apple.

Taking into account packaging and moment of purchase. Throughout the year (Scenario B), lowest impacts are found at the beginning of the season (October for BE apples or April for NZ apples). When it comes to packaging methods (Scenario C), impacts of bulk apples are always lower than their pre-packed counterparts. Looking at all possible combinations of packaging method and moment of purchase (Scenario D), minimum values are found 
for bulk apples in October or April for BE and NZ apples respectively, while maximum values for pre-packed apples in September.

For BE apples, the moment of purchase very much affects the IRHH impact of the apples being bought, while for the other impact categories it is the choice of packaging method that has the greatest potential for lowering the impact: in all but two ICs, about $10 \%$ or higher reductions can be achieved by consuming only bulk apples rather than what is currently consumed (60\% pre-packed apples, $40 \%$ bulk). When it comes to NZ apples, the best way to reduce the impact is through buying only bulk apples. Reductions are however smaller than for BE apples and even when choosing the most environment friendly alternative, the BE apple would still have a lower impact than its imported counterpart.

There is potential to lower the impact of apples by altering the secondary packaging materials being used along the BE apple chain. This study found that a switch to using only EPS plastic crates at the auction or sorting facility (rather than a mix of cardboard boxes and plastic crates) would lead to reductions between 7\% (MEU) and 46\% (MD) for an average $\mathrm{kg} \mathrm{BE}$ apples (Scenario A). We therefore suggest looking into switching to using more, if not only, EPS crates for secondary packaging. We also suggest looking into the possibilities of using plastic crates for distribution of NZ apples, including the logistics necessary to set up a global pool system for the crates (along the lines of the Europool system) and taking into account all environmental impacts associated with such a system.

Food waste along the chain. Impacts resulting from food waste along the supply chain and at the consumer can be categorised as impacts associated with apples lost along the supply chain (and thus never purchased or consumed), apples purchased and eaten by the consumer, and apples purchased but lost and thus never consumed. In all but two ICs, $10 \%$ or more of the impact associated with the apple food chain refers to apples that entered the food chain but were in the end not consumed. The smallest impacts associated with food losses along the supply chain and at the consumer are found for BE apples within the impact category MD. In the FEU impact category on the other hand, the relative impact associated with the losses is at its largest, mounting to almost $30 \%$, stemming mainly from food losses along the supply chain and in particular from the disposal of these losses. This shows the potential for lowering the impact along the chain through the reduction of food losses both along the supply chain as well as by the consumer. Additionally, it shows the importance of the way these food wastes are being treated.

At this moment, one spoiled pre-packed apple in the shop results in throwing away an entire package of six apples. We recommend looking into the possibilities of reducing losses in the shop for pre-packed apples, in particular the possibility of throwing away only the spoiled apples while the remaining good apples are put aside for human consumption (such as put for sale as bulk apples or give to charity). Additionally, other causes for food waste along the supply chain must be investigated; the study of Mena et al. (2011) may provide interesting guidance in this. Finally, we believe that also consumers should gain awareness of the impact their food wastages have on the environment and should be stimulated to reduce food waste in their homes. 


\section{Acknowledgements}

The authors greatly acknowledge the support of the Science, Engineering and Technology Group at KU Leuven for the Expertise Centre Ethics@ Arenberg.

\section{References}

Alexander P, Brown C, Arneth A, et al (2017) Losses, inefficiencies and waste in the global food system. Agric Syst 153:190-200. doi: 10.1016/j.agsy.2017.01.014

Barthel L, Albrecht S, Baitz M, et al (2007) The Sustainability of Packaging Systems for Fruit and vegetable Transport in Europe based on Life-cycle-Analysis. Report on behalf of Stiftung Initiative Mehrweg, Germany.

Berrens P (2016) "Duurzaamheid in de voedselketen : stay local or go global?" (Sustainability in the food chain: stay local or go global?). Master thesis, M.Sc. Bioscience Engineering. KU Leuven, Belgium

BFV (2017) Overview packaging materials. Belgische Fruitveiling (BFV)/Belgian Fruit Auction, St Truiden, Belgium. (http://www.bfv.be/uploadcms/documents/BFV_verpakking-overzicht_OK.pdf).

Blanke M, Burdick B (2005) Food (miles) for Thought. Energy balance for locally grown vs imported apple fruit. Environ Sci Pollut Res 12:125-127. doi: 10.1065/espr2005.05.252

Blonk Agri-footprint (2015) Agri - footprint 2.0. Part 2: Description of data. Blonk Agri-footprint, Gouda, The Netherlands

Cerutti AK, Beccaro GL, Bruun S, et al (2014) Life cycle assessment application in the fruit sector: State of the art and recommendations for environmental declarations of fruit products. J Clean Prod 73:125-135. doi: 10.1016/j.jclepro.2013.09.017

Cuellar AD, Webber ME (2010) Wasted Food, Wasted Energy: The Embedded Energy in Food Waste in the United States. Environ Sci Technol 44:6464-6469.

Davis J, Wallman M, Sund V, et al (2011) Emissions of Greenhouse Gases from Production of Horticultural Products - Analysis of 17 products cultivated in Sweden. SR 828. Swedish Institute for Food and Biotechnology (SIK), Gothenburg, Sweden

defra (2010) Household Food and Drink Waste linked to Food and Drink Purchases. Foss House, Kings Pool, 1 2 Peasholme Green, York, UK

Eberle U, Fels J (2016) Environmental impacts of German food consumption and food losses. Int J Life Cycle Assess 21:759-772. doi: 10.1007/s11367-015-0983-7

ECOFYS, RDC, PRé (2017) Webinar on how to perform a hotspot analysis (in context of the EF pilot phase of the European Commission DG-ENV).

EPS (2017) EuroPoolSystem, blue rigid trays. http://www.europoolsystem.com/en/Trays/Blue-rigid-tray. Last accessed on 6 October 2017.

European Commission (2013a) $\operatorname{COM(2013)196.~Communication~from~the~Commission~to~the~European~}$ Parliament and the Council. Building the Single Market for Green Products. European Commission, Brussels, Belgium

European Commission (2016) Product Environmental Footprint Guidance. Guidance for the development of Product Environmental Footprint Category Rules (PEFCRs), Version 6.0, November 2016. European Commission, Brussels, Belgium

European Commission (2013b) Commission Recommendation of 9 April 2013 on the use of common methods to measure and communicate the life cycle environmental performance of products and organisations (2013/179/EU). European Commission, Brussels, Belgium 
FAO (2013) Food wastage footprint. Impacts on natural resources. Summary report. FAO, Food and Agriculture Organisation, Rome, Italy

Godfray HCJ, Beddington JR, Crute IR, et al (2010) Food security: the challenge of feeding 9 billion people. Science 327:812-8. doi: 10.1126/science.1185383

Goossens Y, Annaert B, De Tavernier J, et al (2017a) Life cycle assessment (LCA) for apple orchard production systems including low and high productive years in conventional, integrated and organic farms. Agric Syst 153:81-93. doi: 10.1016/j.agsy.2017.01.007

Goossens Y, Berrens P, Charleer L, et al (2017b) Qualitative assessment of eco-labels on fresh produce in Flanders (Belgium) highlights a potential intention-performance gap for the supply chain. J Clean Prod 140:986-995. doi: 10.1016/j.jclepro.2016.05.063

Gustavsson J, Cederberg C, Sonesson U, et al (2011) Global Food Losses and Food Waste. Extent, causes and prevention. Swedish Institute for Food and Biotechnology (SIK), Gothenburg, Sweden

Hanson C, Mitchell P (2017) The Business Case for Reducing Food Loss and Waste. Champions 123 1-24.

Hepting DH, Jaffe J, Maciag T (2013) Operationalizing Ethics in Food Choice Decisions. J Agric Environ Ethics 27:453-469. doi: 10.1007/s10806-013-9473-8

Hic C, Pradhan P, Rybski D (2016) Food Surplus and Its Climate Burdens. Environ Sci Technol. doi: 10.1021/acs.est.5b05088

Hospido A, Milà i Canals L, McLaren S, et al (2009) The role of seasonality in lettuce consumption: a case study of environmental and social aspects. Int J Life Cycle Assess 14:381-391. doi: 10.1007/s11367-009-0091-7

Huygens D, Lips D, Aerts S (2010) Short Chain Food Supply in Flanders ( Belgium ): Direct Sales of Farm Made Products. Bull Univ Agric Sci Vet Med Cluj-Napoca 67:154-160.

Ilbery B, Maye D (2005) Food supply chains and sustainability: evidence from specialist food producers in the Scottish/English borders. Land use policy 22:331-344. doi: 10.1016/j.landusepol.2004.06.002

Ingwersen WW (2012) Life cycle assessment of fresh pineapple from Costa Rica. J Clean Prod 35:152-163. doi: 10.1016/j.jclepro.2012.05.035

Ingwersen WW, Stevenson MJ (2012) Can we compare the environmental performance of this product to that one? An update on the development of product category rules and future challenges toward alignment. J Clean Prod 24:102-108. doi: 10.1016/j.jclepro.2011.10.040

IPCC (2006a) 2006 IPCC Guidelines for National Greenhouse Gas Inventories. Volume 4: Agriculture, Forestry and Other Land Use. Chapter 11: N2O emissions from managed soils, and CO2 emissions from lime and urea application. Geneva, Switzerland

IPCC (2006b) 2006 IPCC Guidelines for National Greenhouse Gas Inventories. Volume 2: Energy. Chapter 2: Stationary Combustion. Geneva, Switzerland

Johnson D, Hipps N, Hails S (2008) Helping Consumers Reduce Fruit and Vegetable Waste: Final Report. WRAP UK. Available at http://www.wrap.org.uk/sites/files/wrap/WRAP\%20RTL044001\%20Final\%20report.pdf

Jones A (2002) An Environmental Assessment of Food Supply Chains: A Case Study on Dessert Apples. Environ Manage 30:560-576. doi: 10.1007/s00267-002-2383-6

Keyes S, Tyedmers P, Beazley K (2015) Evaluating the environmental impacts of conventional and organic apple production in Nova Scotia, Canada, through life cycle assessment. J Clean Prod 104:40-51. doi: 10.1016/j.jclepro.2015.05.037

Longo S, Mistretta M, Guarino F, Cellura M (2017) Life Cycle Assessment of organic and conventional apple supply chains in the North of Italy. J Clean Prod 140:654-663. doi: 10.1016/j.jclepro.2016.02.049

Loureiro ML, Mccluskey JJ, Mittelhammer RC (2002) Will Consumers Pay a Premium for Eco-labeled Apples? 
Mena C, Adenso-Diaz B, Yurt O (2011) The causes of food waste in the supplier-retailer interface: Evidences from the UK and Spain. Resour Conserv Recycl 55:648-658. doi: 10.1016/j.resconrec.2010.09.006

Milà i Canals L, Cowell SJ, Sim S, Basson L (2007) Comparing domestic versus imported apples: A focus on energy use. Environ Sci Pollut Res - Int 14:338-344. doi: 10.1065/espr2007.04.412

Milà i Canals L, Muñoz I, Hospido A, et al (2008) Life cycle assessment (LCA) of domestic vs imported vegetables. Case studies on broccoli, salad crops and green beans. CES working paper 01/08. Centre for Environmental Strategy, University of Surrey, UK

Mithraratne N, McLaren S, Barber A (2008) Carbon footprinting for the kiwifruit supply chain: methodology and scoping study. Report to Ministry of Agriculture and Forestry, New Zealand.

Mundler P, Rumpus L (2012) The energy efficiency of local food systems: A comparison between different modes of distribution. Food Policy 37:609-615. doi: 10.1016/j.foodpol.2012.07.006

Muñoz I, Canals LMI, Clift R (2008) Consider a spherical man: A simple model to include human excretion in life cycle assessment of food products. J Ind Ecol 12:521-538. doi: 10.1111/j.1530-9290.2008.00060.x

Nemecek T, Kagi T (2007) Life cycle inventories of Agricultural Production Systems, ecoinvent report No. 15. Agroscope Reckenholz-Tänikon Research Station ART, Zurich, Switzerland

Nemecek T, Schnetzer J (2011) Methods of assessment of direct field emissions for LCIs of agricultural production systems. Data v3.0 (2012). Agroscope Reckenholz-Tänikon Research Station ART, Zurich, Switzerland

Notarnicola B, Tassielli G, Renzulli PA, et al (2017) Environmental impacts of food consumption in Europe. J Clean Prod 140:753-765.

Robertson K, Garnham M, Symes W (2014) Life cycle carbon footprint of the packaging and transport of New Zealand kiwifruit. Int J Life Cycle Assess 19:1693-1704. doi: 10.1007/s11367-014-0775-5

Röös E, Karlsson H (2013) Effect of eating seasonal on the carbon footprint of Swedish vegetable consumption. J Clean Prod 59:63-72. doi: 10.1016/j.jclepro.2013.06.035

Saunders C, Barber A (2008) Carbon Footprints, Life Cycle Analysis, Food Miles: Global Trade Trends and Market Issues. Polit Sci 60:73-88. doi: 10.1177/003231870806000107

Scholz K, Eriksson M, Strid I (2015) Carbon footprint of supermarket food waste. Resour Conserv Recycl 94:5665. doi: 10.1016/j.resconrec.2014.11.016

Sim S, Barry M, Clift R, Cowell SJ (2007) The relative importance of transport in determining an appropriate sustainability strategy for food sourcing. A case study of fresh produce supply chains. Int J Life Cycle Assess 12:422-431. doi: 10.1065/lca2006.07.259 Please

Svanes E, Aronsson AKS (2013) Carbon footprint of a Cavendish banana supply chain. Int J Life Cycle Assess 18:1450-1463. doi: 10.1007/s11367-013-0602-4

Van Hauwermeiren A, Coene H, Engelen G, Mathijs E (2007) Energy Lifecycle Inputs in Food Systems: A Comparison of Local versus Mainstream Cases. J Environ Policy Plan 9:31-51. doi: $10.1080 / 15239080701254958$

Vinyes E, Asin L, Alegre S, et al (2017) Life Cycle Assessment of apple and peach production, distribution and consumption in Mediterranean fruit sector. J Clean Prod 149:313-320. doi: 10.1016/j.jclepro.2017.02.102

WRAP (2008) The food we waste. Food waste report v2. Banbury, UK. Available at http://wrap.s3.amazonaws.com/the-food-we-waste.pdf. 


\section{TABLES}

Table 1 Packaging mix: share (\%) of apples being sold as bulk or as pre-packaged apples, for apples coming from BE and NZ (data provided by Colruyt Group).

\begin{tabular}{llcc}
\hline Packaging & Primary packaging materials (weight) & BE & NZ \\
\hline Bulk & Plastic bag available in shop (4.90g) & $40 \%$ & $23 \%$ \\
\hline Pre-packaged & $\begin{array}{l}\text { Packaging per 6 using a cardboard tray (21.00g) } \\
\text { and plastic film (3.21g) }\end{array}$ & $60 \%$ & $77 \%$ \\
& & & \\
\hline
\end{tabular}

Table 2 Moment mix: shares (\%) of BE and NZ apples sold per month throughout the year (data provided by Colruyt Group).

\begin{tabular}{|c|c|c|c|c|c|c|c|c|c|c|c|c|c|}
\hline & 1 & 2 & 3 & 4 & 5 & 6 & 7 & 8 & 9 & 10 & 11 & 12 & Total \\
\hline BE & 10.38 & 10.40 & 11.54 & 10.30 & 7.19 & 6.80 & 3.92 & 4.04 & 7.70 & 8.56 & 9.51 & 9.67 & $100 \%$ \\
\hline NZ & . & . & . & 5.75 & 20.50 & 22.04 & 23.53 & 22.27 & 5.91 & 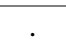 & . & . & $100 \%$ \\
\hline
\end{tabular}

Table 3 Scenarios investigated for $1 \mathrm{~kg}$ apples purchased by a consumer in the supermarket.

\begin{tabular}{lll}
\hline Scenario & Packaging & Moment of purchase \\
\hline $\begin{array}{l}\text { Scenario A : } \\
\text { Reference flow }\end{array}$ & Packaging mix (Table 1), weighted average & Moment mix (Table 2), weighted average \\
\hline Scenario B & Packaging mix (Table 1), weighted average & Per month: 12 months for BE apple (Jan.-Dec.); \\
& & 6 months for NZ apple (April - Sept.) \\
\hline Scenario C & Per packaging method: Bulk packaging vs & Moment mix (Table 2), weighted average \\
& pre-packed per 6 & \\
\hline Scenario D & Per packaging method: Bulk packaging vs & Per month: 12 months for BE apple (Jan.-Dec.); \\
& pre-packed per 6 & 6 months for NZ apple (April - Sept.) \\
\hline
\end{tabular}


Table 4 Impact along the entire chain for the relevant ICs: impacts associated with $1 \mathrm{~kg} \mathrm{BE}$ or NZ apples within Scenario A and minimum and maximum impacts within Scenarios B, C and D.

\begin{tabular}{|c|c|c|c|c|c|c|c|c|c|}
\hline \multirow[b]{3}{*}{ IC } & \multirow[b]{3}{*}{ Unit } & \multirow[b]{3}{*}{ Origin } & \multicolumn{7}{|c|}{ Scenario } \\
\hline & & & \multirow[t]{2}{*}{$\mathbf{A}$} & \multicolumn{2}{|c|}{ B } & \multicolumn{2}{|c|}{$\mathbf{C}$} & \multicolumn{2}{|c|}{ D } \\
\hline & & & & Min. & Max. & Min. & Max. & Min. & Max. \\
\hline \multirow[t]{2}{*}{$\mathrm{CC}$} & \multirow[t]{2}{*}{$10^{-2} \mathrm{~kg} \mathrm{CO}_{2} \mathrm{eq}$} & $\mathrm{BE}$ & 38.1 & 35.9 & 41.1 & 33.8 & 41.1 & 31.5 & 44.0 \\
\hline & & $\mathrm{NZ}$ & 133 & 132 & 134 & 126 & 135 & 125 & 136 \\
\hline PM & $10^{-5} \mathrm{~kg} \mathrm{PM}_{2.5} \mathrm{eq}$ & $\mathrm{BE}$ & 21.9 & 21.2 & 23.0 & 19.2 & 23.8 & 18.4 & 24.8 \\
\hline IRHH & $10^{-3} \mathrm{kBq} \mathrm{U}^{235} \mathrm{eq}$ & $\mathrm{BE}$ & 93.9 & 68.4 & 127 & 89.0 & 97.2 & 62.9 & 132 \\
\hline POF & $\begin{array}{l}10^{-4} \mathrm{~kg} \mathrm{NMVOC} \\
\text { eq }\end{array}$ & NZ & 157 & 157 & 158 & 153 & 158 & 153 & 159 \\
\hline \multirow[t]{2}{*}{$\mathrm{AC}$} & \multirow[t]{2}{*}{$10^{-4}$ molc $\mathrm{H}^{+}$eq } & $\mathrm{BE}$ & 25.3 & 24.5 & 26.3 & 22.9 & 26.9 & 22.1 & 28.0 \\
\hline & & $\mathrm{NZ}$ & 187 & 187 & 188 & 182 & 189 & 181 & 190 \\
\hline TEU & $10^{-4}$ molc $\mathrm{N}$ eq & $\mathrm{NZ}$ & 614 & 612 & 616 & 600 & 619 & 598 & 621 \\
\hline FEU & $10^{-5} \mathrm{~kg} \mathrm{P} \mathrm{eq}$ & $\mathrm{BE}$ & 11.5 & 11.0 & 12.3 & 9.49 & 12.9 & 8.91 & 13.7 \\
\hline \multirow[t]{2}{*}{ MEU } & \multirow[t]{2}{*}{$10^{-5} \mathrm{~kg} \mathrm{~N}$ eq } & $\mathrm{BE}$ & 97.6 & 95.5 & 100 & 92.7 & 101 & 90.6 & 104 \\
\hline & & $\mathrm{NZ}$ & 574 & 572 & 576 & 560 & 578 & 558 & 580 \\
\hline \multirow[t]{2}{*}{ MD } & \multirow[t]{2}{*}{$10^{-6} \mathrm{~kg} \mathrm{Sb}$ eq } & $\mathrm{BE}$ & 51.9 & 50.0 & 54.4 & 46.4 & 55.6 & 44.5 & 58.2 \\
\hline & & NZ & 197 & 195 & 199 & 187 & 199 & 186 & 202 \\
\hline
\end{tabular}


Table 5 Contributing life cycle (sub)stages to the impacts associated with $1 \mathrm{~kg}$ Belgian and New Zealand apples (Scenario A, reference flow), expressed in percent: hotspots (contributing cumulatively to more than $50 \%$ of the impact) are highlighted in bold. If an IC was found to be non-relevant for BE or NZ apples, the columns are left blank 


\begin{tabular}{|c|c|c|c|c|c|c|c|c|c|c|}
\hline BE apples & & $\mathrm{CC}$ & PM & IRHH & POF & $\mathbf{A C}$ & TEU & FEU & MEU & MD \\
\hline Cultivation & & 16 & 15 & 3 & & 40 & & 15 & 63 & 4 \\
\hline Storage \& sorting & Transport & 6 & 10 & 2 & & 7 & & 5 & 6 & 6 \\
\hline & Storage & 5 & 3 & 28 & & 2 & & 4 & 1 & 3 \\
\hline & Sorting & $<1$ & $<1$ & 1 & & $<1$ & & $<1$ & $<1$ & $<1$ \\
\hline \multirow[t]{3}{*}{ Distribution } & Storage in retail \& DC & 1 & 1 & 6 & & 1 & & 1 & $<1$ & 1 \\
\hline & Transport truck & 9 & 11 & 3 & & 8 & & 2 & 7 & 4 \\
\hline & Overseas transport \& cooling & - & - & - & & - & & - & - & - \\
\hline \multirow[t]{2}{*}{ Packaging } & Primary packaging & 9 & 12 & 5 & & 9 & & 11 & 4 & 3 \\
\hline & Secondary packaging & 15 & 22 & 9 & & 14 & & 24 & 9 & 33 \\
\hline Disposal supply chain & & 12 & 7 & 2 & & 6 & & 22 & 3 & 15 \\
\hline Consumer & & 17 & 16 & 40 & & 10 & & 12 & 5 & 24 \\
\hline Disposal consumer & & 9 & 3 & 1 & & 3 & & 3 & 1 & 7 \\
\hline TOTAL & & $100 \%$ & $100 \%$ & $100 \%$ & & $100 \%$ & & $100 \%$ & $100 \%$ & $100 \%$ \\
\hline NZ apples & & $\mathrm{CC}$ & PM & IRHH & POF & $\mathbf{A C}$ & TEU & FEU & MEU & MD \\
\hline Cultivation & & 4 & & & 2 & 3 & 4 & & 6 & 1 \\
\hline \multirow[t]{3}{*}{ Storage \& sorting } & Transport & $<1$ & & & $<1$ & $<1$ & $<1$ & & $<1$ & $<1$ \\
\hline & Storage & $<1$ & & & $<1$ & $<1$ & $<1$ & & $<1$ & 1 \\
\hline & Sorting & $<1$ & & & $<1$ & $<1$ & $<1$ & & $<1$ & $<1$ \\
\hline \multirow[t]{3}{*}{ Distribution } & Storage in retail \& DC & $<1$ & & & $<1$ & $<1$ & $<1$ & & $<1$ & $<1$ \\
\hline & Transport truck & 5 & & & 2 & 2 & 2 & & 2 & 3 \\
\hline & Overseas transport \& cooling & 68 & & & 90 & 87 & 88 & & 86 & 61 \\
\hline Packaging & Primary packaging & 3 & & & 1 & 1 & 1 & & 1 & 1 \\
\hline
\end{tabular}




\begin{tabular}{l|c|ccccc}
\hline & Secondary packaging & 7 & 3 & 4 & 2 & 1 \\
\hline Disposal supply chain & 5 & 1 & 1 & 1 \\
\hline Consumer & 5 & 1 & 1 & 1 \\
\hline Disposal consumer & 3 & $<$ & $<1$ & 1 \\
\hline TOTAL & $100 \%$ & $100 \%$ & $100 \%$ & $100 \%$ \\
\hline
\end{tabular}


1 Table 6 Comparison of the impacts associated with primary and secondary packaging for $1 \mathrm{~kg}$ bulk and pre-packed BE and NZ

2 apples (Scenario C). If an IC was found to be non-relevant for BE or NZ apples, the impact value is left blank.

\begin{tabular}{|c|c|c|c|c|c|c|c|c|c|}
\hline \multirow[b]{3}{*}{ IC } & \multirow[b]{3}{*}{ Unit } & \multicolumn{4}{|c|}{ Primary packaging } & \multicolumn{4}{|c|}{ Secondary packaging } \\
\hline & & \multicolumn{2}{|c|}{ BE } & \multicolumn{2}{|c|}{ NZ } & \multicolumn{2}{|c|}{ BE } & \multicolumn{2}{|c|}{ NZ } \\
\hline & & bulk & per6 & bulk & per6 & bulk & per6 & bulk & per6 \\
\hline $\mathrm{CC}$ & $10^{-2} \mathrm{~kg} \mathrm{CO}_{2}$ eq & 1.75 & 4.38 & 1.75 & 4.38 & 4.57 & 6.64 & 7.68 & 9.83 \\
\hline $\mathrm{PM}$ & $10^{-5} \mathrm{~kg} \mathrm{PM}_{2.5} \mathrm{eq}$ & 1.30 & 3.46 & & & 4.04 & 5.37 & & \\
\hline IRHH & $10^{-3} \mathrm{kBq} \mathrm{U}^{235} \mathrm{eq}$ & 1.51 & 7.53 & & & 7.19 & 8.92 & & \\
\hline POF & $10^{-4} \mathrm{~kg}$ NMVOC & & & 0.794 & 1.62 & & & 3.50 & 4.31 \\
\hline $\mathrm{AC}$ & $10^{-4} \mathrm{molc} \mathrm{H}^{+}$eq & 1.12 & 2.90 & 1.12 & 2.90 & 2.96 & 3.99 & 5.94 & 7.04 \\
\hline TEU & $10^{-4}$ molc $\mathrm{N}$ eq & & & 2.03 & 4.61 & & & 11.5 & 13.4 \\
\hline FEU & $10^{-5} \mathrm{~kg} \mathrm{P}$ eq & 0.405 & 1.90 & & & 2.46 & 2.94 & & \\
\hline MEU & $10^{-5} \mathrm{~kg} \mathrm{~N}$ eq & 1.94 & 5.03 & 1.94 & 5.03 & 7.60 & 9.35 & 14.6 & 16.5 \\
\hline MD & $10^{-6} \mathrm{~kg} \mathrm{Sb}$ eq & 0.236 & 2.54 & 0.236 & 2.54 & 16.6 & 17.3 & 32.8 & 33.8 \\
\hline
\end{tabular}




\section{FIGURE CAPTIONS}

Figure 1 Flow chart - Visualisation of the Belgian (BE) and New Zealand (NZ) apple chain, for both bulk and pre-packed apples.

9

10

11

12

13

14

15

16

17

18

19

Figure 2 Visualisation of food losses and food waste flows throughout the chain for both BE and NZ bulk and pre-packed apples. Based on the percentage wasted or lost at each step along the chain, the total amount of apples $(\mathrm{kg})$ that needs to go through the chain at each specific stage is given. Note that only the relevant stages along the chain where food waste or losses occurs, are shown. Loss percentages along the supply chain were provided by the auction (BFV and BelOrta), the importing company (Enzafruit) and by the retailer (Colruyt Group). Food wastage by the consumer is based on literature (Johnson et al. 2008; WRAP 2008).

Figure 1 Life cycle impact along the chain for $1 \mathrm{~kg}$ average Belgian or New-Zealand apples purchased by a consumer in the supermarket (scenario A). Only those ICs relevant for either BE or NZ apples, are shown in the graph.

Figure 4 (part a/part b) Life cycle impact along the chain for kg BE or NZ apples purchased by a consumer in the supermarket, visualised throughout the year and for two packaging methods (Scenario D). Only those ICs relevant for either BE or NZ apples are shown in the graph.

Figure 5 Percentage contribution of each life cycle stage to the impacts associated with $1 \mathrm{~kg}$ Belgian and New Zealand apples purchased by a consumer in the supermarket (Scenario A, reference flow). If an IC was found to be non-relevant for BE or NZ apples, the impact values are left blank.

Figure 6 Allocation of the total impacts associated with $1 \mathrm{~kg}$ Belgian and New Zealand apples purchased by a consumer in the supermarket (Scenario A, reference flow) based on their destination. Impacts are split as follows: allocation of impacts to apples that entered the food chain but never made it to the consumer ("not purchased"), apples that were purchased and eaten by the consumer ("purchased \& eaten"), and apples purchased by the consumer and not eaten but thrown instead ("purchased \& thrown"). Only the relevant ICs are shown. Information on the percentage impacts as visualized in the graph can be found in Online Resource 2 (sheet 10).

Figure 7 Effect of taking into account moment of purchase (Scenario B), packaging method (Scenario C) or a combination of both (Scenario D) for BE and NZ apples. Visualisation of the maximal decrease and increase of the impact found within each of these scenarios, as compared with the average $1 \mathrm{~kg} \mathrm{BE}$ or NZ apples purchased by a consumer (Scenario A, as indicated with a red line), based on the minima and maxima values within each Scenario. Only the relevant impact categories are shown.

Figure 8 Impact reductions for $1 \mathrm{~kg}$ Belgian apples purchased by a consumer (Scenario A and C) when using only EPS M boxes for secondary packaging throughout the supply chain, as compared to the current situation in which 50\% EPS M crates and 50\% cardboard boxes are used. Those ICs for which secondary packaging was found to be a hotspot, are indicated with an asterisk. 


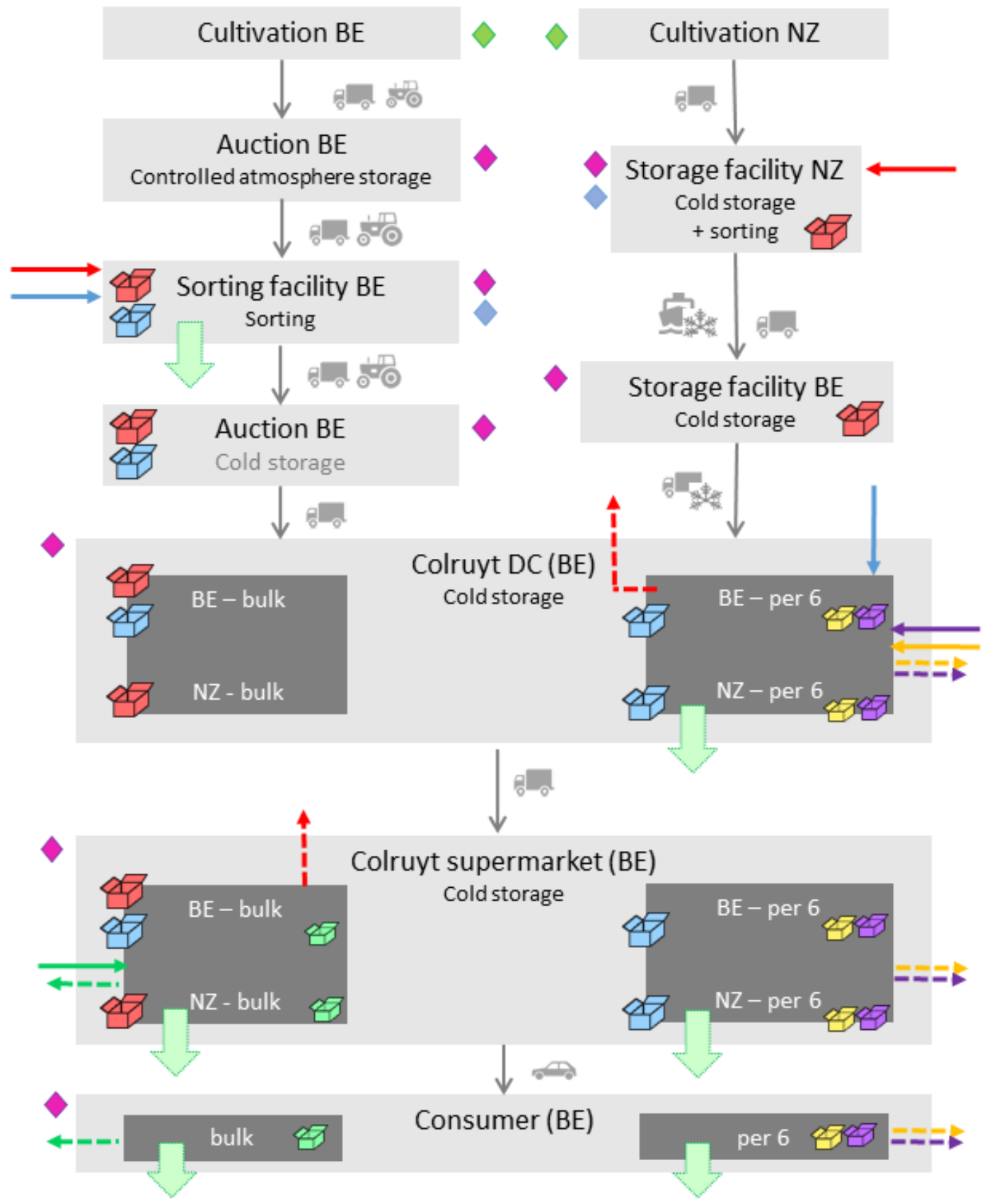

LEGEND
PACKAGING: input $(\longrightarrow$ ), use ( $)$ ) and waste flow $(-\rightarrow)$
Secondary packaging
Primary packaging
Cardboardbox



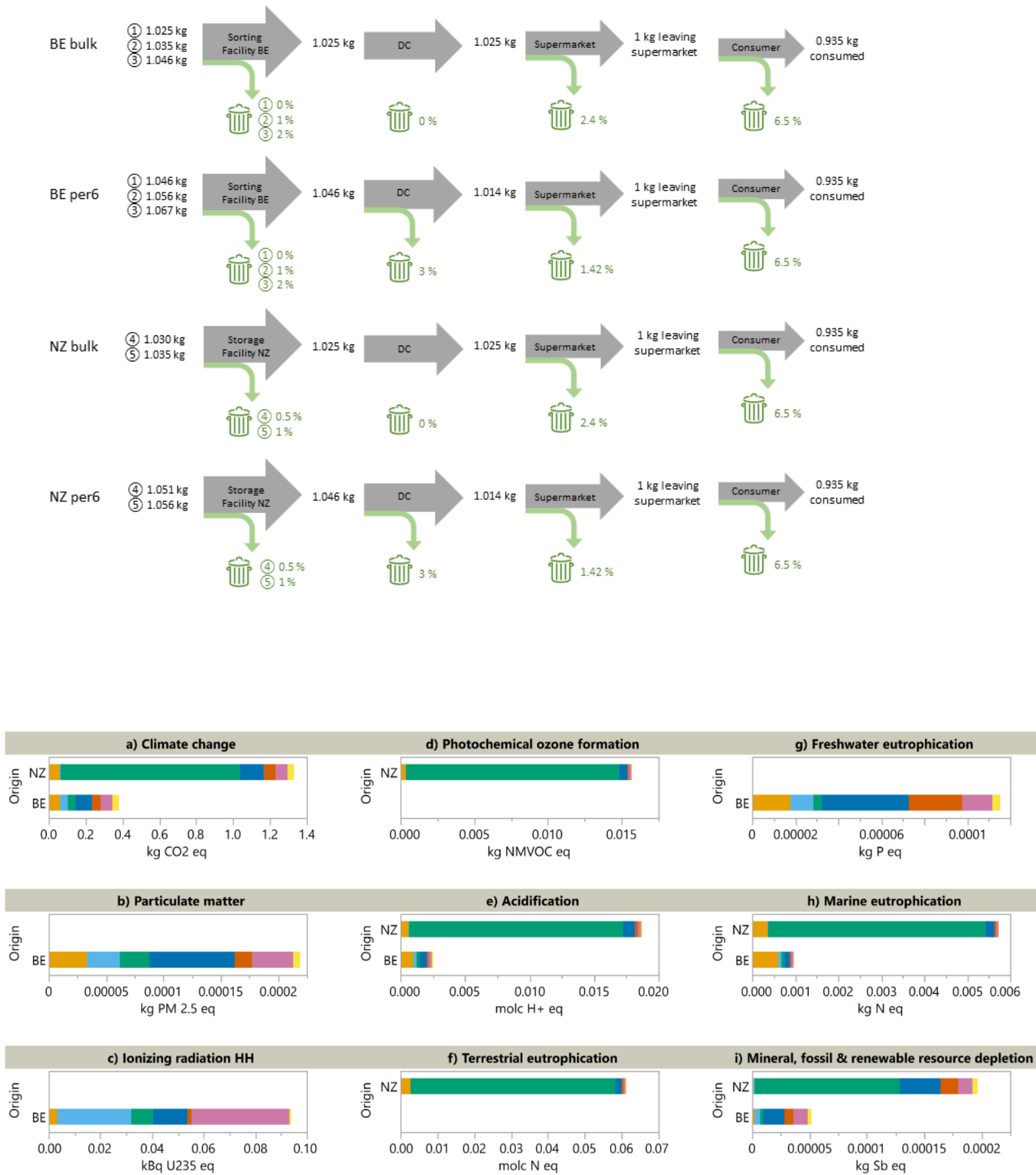

Life cycle stages:

Cultivation

Distribution (DC, retail, transport) 

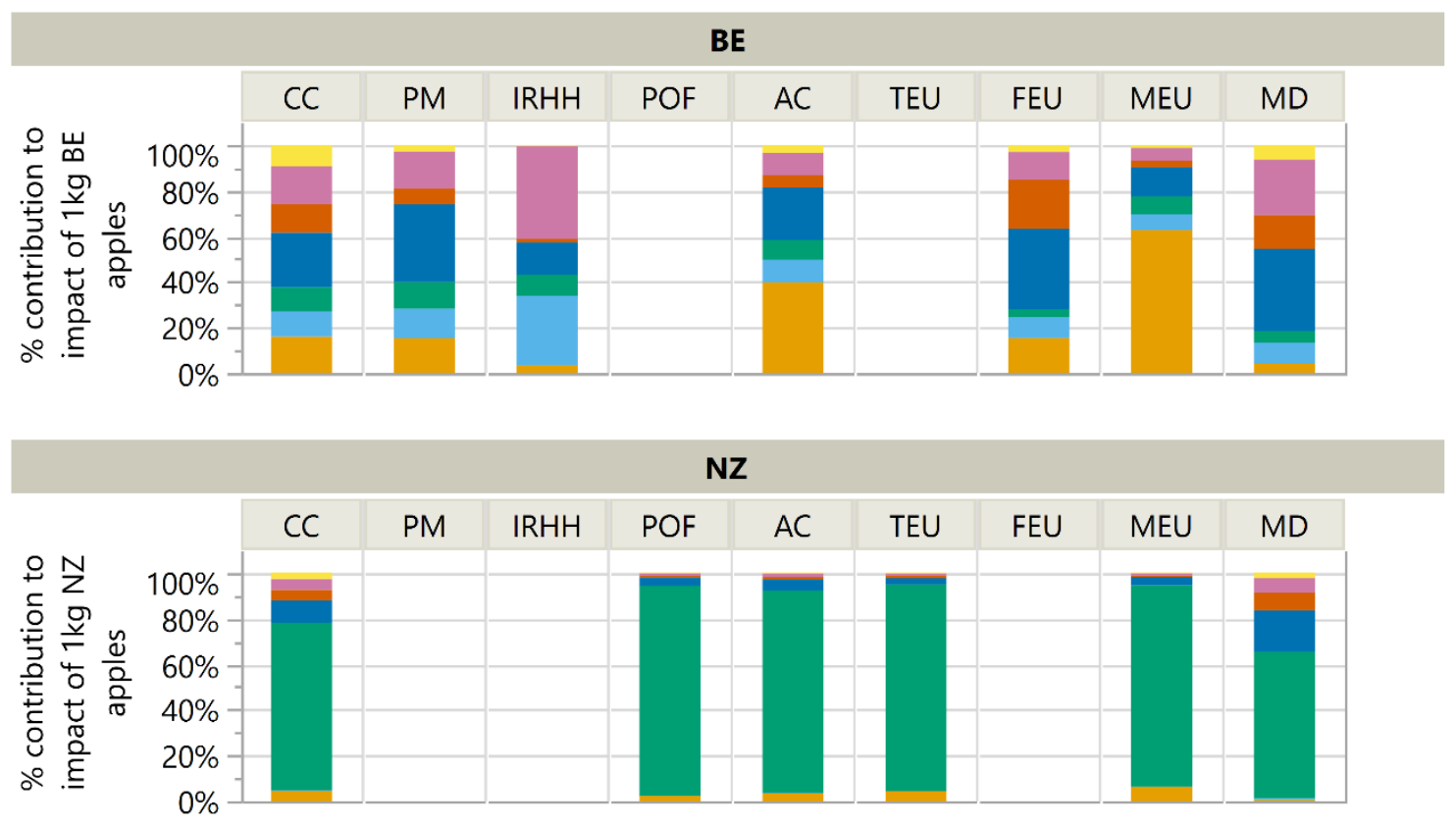

Life cycle stages:

Cultivation, \%

Storage and sorting, \%

Distribution (DC, retail, transport), \%

Packaging (primary \& secondary; excl. disposal), \%

Disposal @ Supply chain, \%

Consumer (transport, storage), \%

Disposal @ Consumer, \%

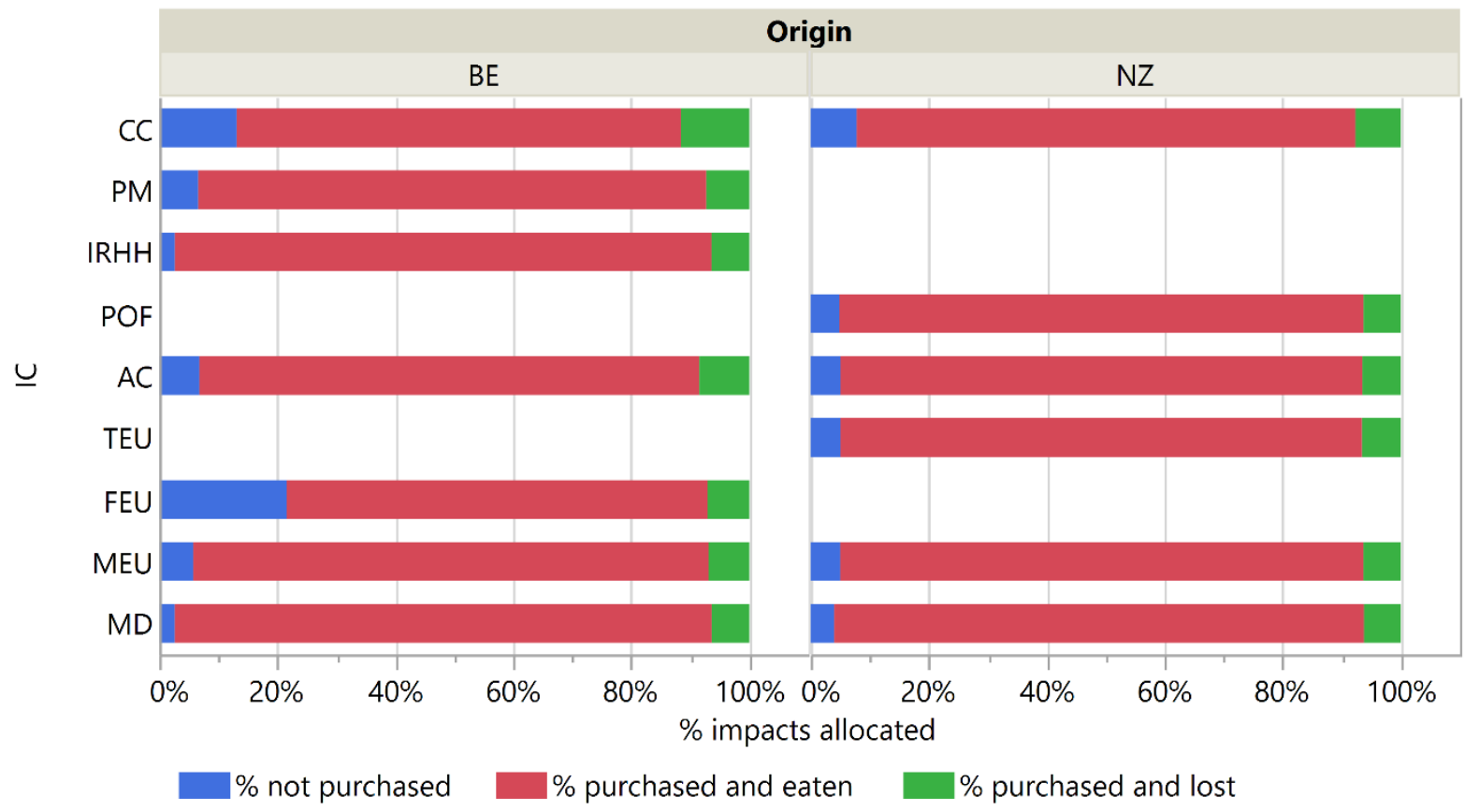




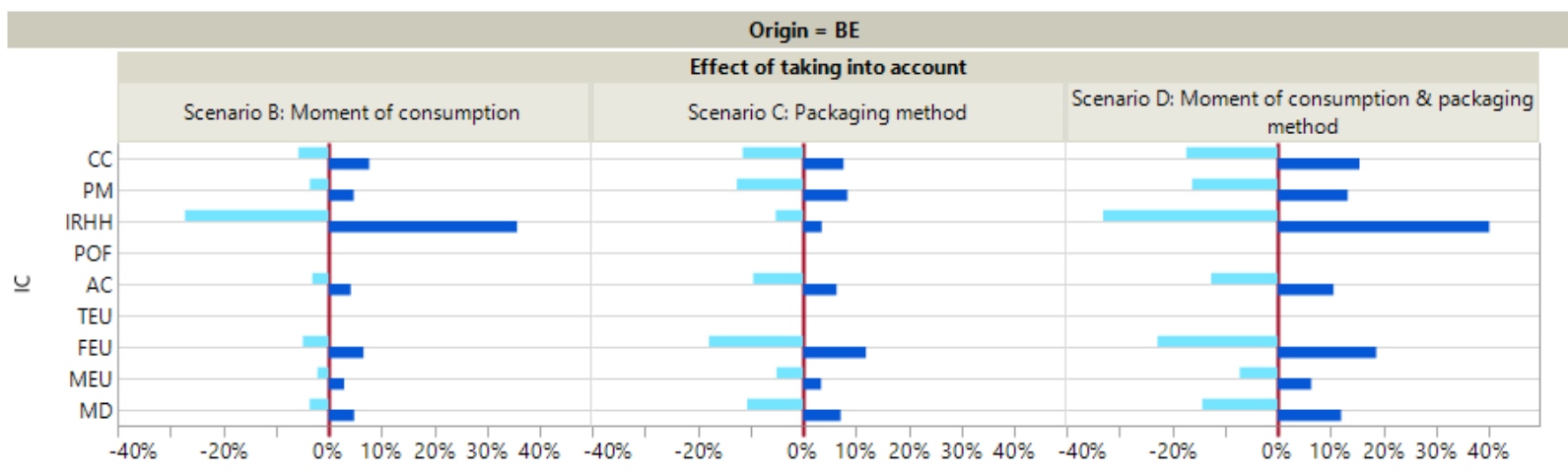

Origin $=\mathrm{NZ}$


Scenario A Scenario C, per $6 \quad$ Scenario $C$, bulk 


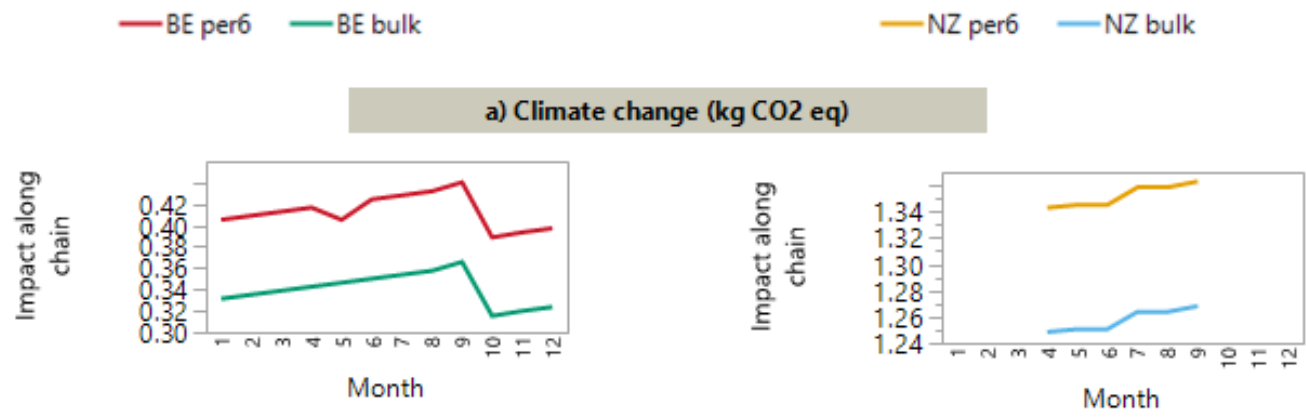

b) Particulate matter (kg PM 2.5 eq)

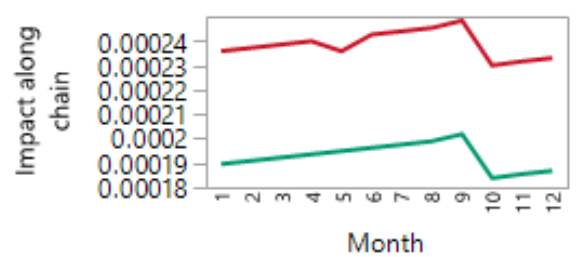

c) lonizing radiation $\mathrm{HH}$ (kBq $\mathrm{U} 235$ eq)

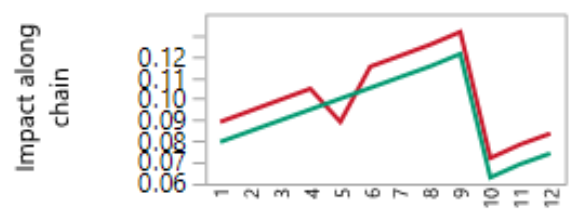

Month

d) Photochemical ozone formation (kg NMVOC eq)
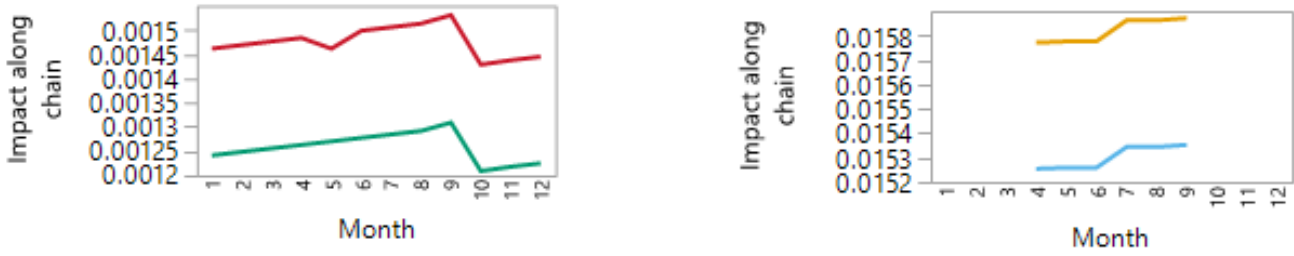

e) Acidification (molc $\mathrm{H}+$ eq)
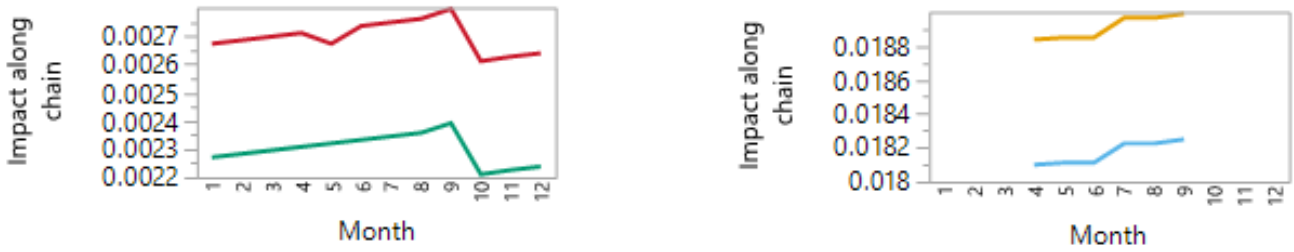

f) Terrestrial eutrophication (molc $\mathrm{N}$ eq)

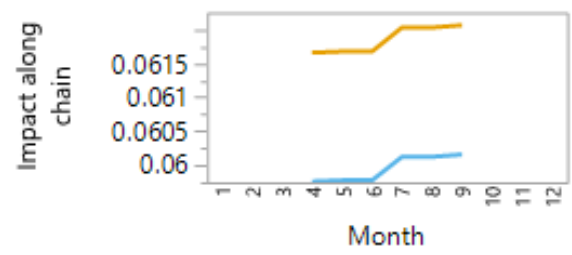




$$
\text { -BE per6 —BE bulk -NZ per6 - NZ bulk }
$$

g) Freshwater eutrophication ( $k g$ P eq)

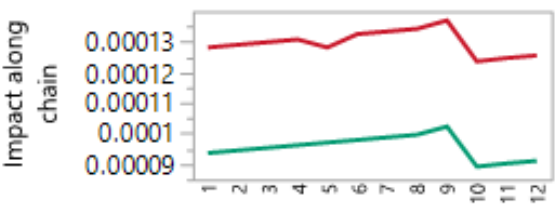

Month

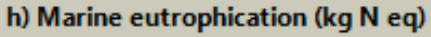

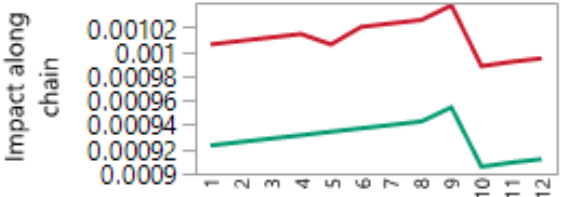

Month

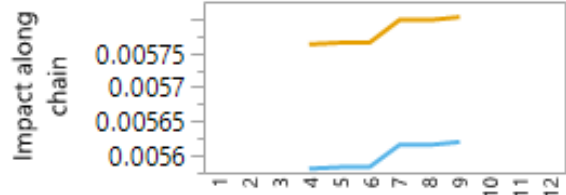

Month

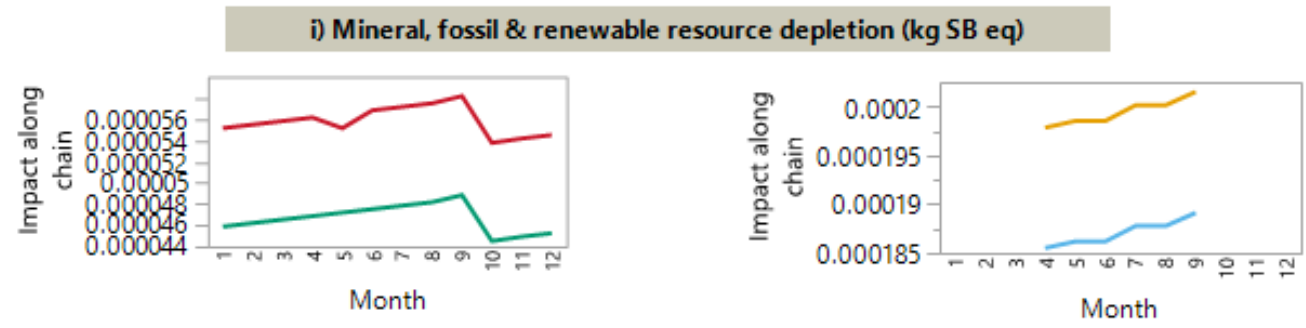


